\title{
The Acute Cardiorespiratory and Cerebrovascular Response to Resistance Exercise
}

\author{
Blake G. Perry ${ }^{1 *}$ (D) and Samuel J. E. Lucas ${ }^{2}$
}

\begin{abstract}
Resistance exercise (RE) is a popular modality for the general population and athletes alike, due to the numerous benefits of regular participation. The acute response to dynamic RE is characterised by temporary and bidirectional physiological extremes, not typically seen in continuous aerobic exercise (e.g. cycling) and headlined by phasic perturbations in blood pressure that challenge cerebral blood flow (CBF) regulation. Cerebral autoregulation has been heavily scrutinised over the last decade with new data challenging the effectiveness of this intrinsic flow regulating mechanism, particularly to abrupt changes in blood pressure over the course of seconds (i.e. dynamic cerebral autoregulation), like those observed during RE. Acutely, RE can challenge CBF regulation, resulting in adverse responses (e.g. syncope). Compared with aerobic exercise, RE is relatively understudied, particularly highintensity dynamic RE with a concurrent Valsalva manoeuvre (VM). However, the VM alone challenges CBF regulation and generates additional complexity when trying to dissociate the mechanisms underpinning the circulatory response to RE. Given the disparate circulatory response between aerobic and RE, primarily the blood pressure profiles, regulation of CBF is ostensibly different. In this review, we summarise current literature and highlight the acute physiological responses to $R E$, with a focus on the cerebral circulation.
\end{abstract}

Keywords: Resistance exercise, Cerebral blood flow, Blood pressure, Valsalva manoeuvre

\section{Key Points}

- Dynamic resistance exercise produces a profoundly different haemodynamic response to aerobic type exercise, including the cerebral blood flow profile. Therefore, the relative contribution of regulatory mechanisms governing cerebral blood flow likely differs greatly between exercise types. Specificity is required when describing exercise to elucidate the underlying physiological mechanisms/responses.

- The type of muscular contraction dictates the blood pressure and cerebral blood flow profile during resistance exercise, further complicated by recruitment of the Valsalva manoeuvre. The Valsalva

\footnotetext{
* Correspondence: B.G.Perry@Massey.ac.nz

${ }^{1}$ School of Health Sciences, Massey University, Wellington, New Zealand

Full list of author information is available at the end of the article
}

manoeuvre exacerbates the within-exercise blood pressure, although is associated with acute reductions in cerebral blood flow and increased risk of postexercise syncope.

- The ability to accurately measure cerebral blood flow during exercise is problematic, restricting investigations to certain exercises and precludes the recruitment of the Valsalva manoeuvre.

\section{Introduction}

Resistance exercise (RE) produces many favourable physiological outcomes that include increased muscular strength, metabolism and alterations in lean body mass [1]. Recently, RE has gained in popularity and is considered an integral part of general health and wellbeing, countering the age-related decline in muscle mass [2] and recommended in combination with regular aerobic

\section{Springer Open}

(๑) The Author(s). 2021 Open Access This article is licensed under a Creative Commons Attribution 4.0 International License, which permits use, sharing, adaptation, distribution and reproduction in any medium or format, as long as you give appropriate credit to the original author(s) and the source, provide a link to the Creative Commons licence, and indicate if changes were made. The images or other third party material in this article are included in the article's Creative Commons licence, unless indicated otherwise in a credit line to the material. If material is not included in the article's Creative Commons licence and your intended use is not permitted by statutory regulation or exceeds the permitted use, you will need to obtain permission directly from the copyright holder. To view a copy of this licence, visit http://creativecommons.org/licenses/by/4.0/. 
exercise to maintain physical function during ageing [3]. Furthermore, RE appears neuroprotective, with transient increases in brain-derived neutrophic factor, a key biomarker linked to neurogenesis and neuronal survival [4], reported immediately following exercise cessation $[5,6]$. More recently, $\mathrm{RE}$ is recommended as treatment for clinical cohorts, including type II diabetes mellitus $[7,8]$, stroke [9] and heart disease [10, 11]. Although rare, the acute extreme hypertension experienced during RE has potential to produce cerebrovascular injury [12, 13], with intense physical activity and the Valsalva manoeuvre (VM) identified as independent triggers of intracranial aneurysm rupture [14]. More common is the risk of syncope immediately following exercise cessation [15], which has the potential to cause trauma related injury. Nevertheless, the benefits of RE are vast and regular participation should be promoted to support physical wellbeing.

The term RE encompasses multiple variations of generating muscular force against an external load and can be subdivided into static and dynamic exercise. The terms, static and dynamic, refer to the type of muscular contraction performed. Static refers to an isometric contraction, sustained for a given period (e.g. $15 \mathrm{~s}$ ); whilst dynamic generally refers to a repetitive movement cycle that consists of distinct concentric and eccentric phases (changes in muscle length), with an associated change in joint angle. Each complete cycle is termed a repetition, with a set comprising of a given number of repetitions. In addition, some research has utilised rhythmic exercise, consisting of static contractions interspersed with relaxation of varying duty cycles. The distinction between the types of RE dictates the haemodynamic response, with key differences discussed herein.

\section{Review Scope}

The review will focus primarily on data from healthy and young ( $<40$ years of age) participants. The review will first briefly cover cerebrovascular regulation to contextualise the regulatory mechanisms that will be active during RE. From here, the review is divided into three main sections. The first section will discuss the physiological response to the VM in isolation and in relation to RE. The second section will discuss the haemodynamic response during RE; including differences between exercise type (static versus dynamic) and the effects of exercise intensity. The final section covers the response immediately following RE. Methodology regarding the measurement of cerebral blood flow (CBF) is also considered.

\section{Regulation of Cerebral Blood Flow}

The brain displays differential regulation compared to other vascular beds. It is immensely sensitive to carbon dioxide $\left(\mathrm{CO}_{2}\right)$, far more so than the skeletal muscle [16], and the parenchyma is extremely ischemia intolerant, with limited ability for metabolic substrate storage and an extraordinarily high metabolic rate [17]. As such, $\mathrm{CBF}$ is under fine control at rest, and exercise, modulated by a plethora of variables that include neurovascular coupling (NVC) [18], cerebral perfusion pressure (CPP) [19], humoral factors (e.g. partial pressure of arterial $\mathrm{CO}_{2}$ and $\mathrm{O}_{2}$ ) [20,21], cardiac output [22] and the autonomic nervous system [23-25].

At rest, the partial pressure of arterial carbon dioxide $\left(\mathrm{P}_{\mathrm{a}} \mathrm{CO}_{2}\right)$ appears to be the most potent and dominating regulator of CBF [26]. Reductions in $\mathrm{P}_{\mathrm{a}} \mathrm{CO}_{2}$ (hypocapnia) stimulate vasoconstriction of cerebral arterioles, increasing cerebrovascular resistance and ultimately reducing CBF [27]. Conversely, increases in $\mathrm{P}_{\mathrm{a}} \mathrm{CO}_{2}$ (hypercapnia) vasodilate cerebral arterioles, reducing cerebrovascular resistance and elevating $\operatorname{CBF}[28,29]$. The regulatory hierarchy persists during exercise, and during aerobic exercise, the CBF profile resembles an inverted $\mathrm{U}$, initial increases to moderate intensities $(50-80 \%$ of maximal workload) with hypocapnic-induced reductions evident at maximal exercise [30]; albeit mostly studied in cycling-based aerobic exercise.

Whilst the current body of knowledge describes the role of $\mathrm{CO}_{2}$ in cerebral perfusion comprehensively, the regulation of $\mathrm{CBF}$ during changes in $\mathrm{CPP}$ has not been as straightforward. Cerebral autoregulation refers to the process by which $\mathrm{CBF}$ is held relatively constant despite varying perfusion pressure [31]. When CPP increases cerebral vessels vasoconstrict, limiting hyperperfusion, conversely, when CPP is decreased cerebral vessels dilate to maintain CBF $[17,32]$. The effectiveness of cerebral autoregulation has been recently challenged [33, 34], with the autoregulatory plateau much narrower than previously described $[35,36]$. This is pertinent given the hallmark of dynamic RE is large sinusoidal changes in mean arterial pressure (MAP). Furthermore, the modulators of $\mathrm{CBF}$ described above are intertwined and not active in isolation. This is exemplified by the interaction between cerebral autoregulation and $\mathrm{P}_{\mathrm{a}} \mathrm{CO}_{2}$, whereby hypocapnia improves cerebral autoregulation while hypercapnia impairs it [19]. Discussion of CBF modulators in detail is beyond the scope of this review, and the reader is directed to more comprehensive reviews of CBF regulation at rest [17, 32, 37, 38] and exercise [30]. Nevertheless, there are some unique aspects of RE that need to be considered in the context of CBF regulation.

\section{The Valsalva Manoeuvre}

Traditionally, the VM is performed by forceful exhalation against a closed glottis and used in everyday activities such as lifting [39], defecation and coughing [40]. In isolation the VM produces a complex cardiovascular response [41], used clinically to test dynamic cerebral 
autoregulation [42, 43] and autonomic function [44]. There are 4 distinct phases of the VM (see Fig. 1). The first (phase I) is characterised by a transient MAP spike as increased intrathoracic pressure is translated to the arterial tree [40]. Approximately $3 \mathrm{~s}$ into the strain, atrial filling (phase IIa) declines $[39,46]$, reducing stroke volume (SV) and subsequently MAP. Arterial baroreflexmediated increases in heart rate (phase IIb) generate a partial recovery of MAP until the strain is released. Upon strain cessation, blood floods the distended pulmonary vessels and the reduction in intrathoracic pressure decompresses the thoracic arteries, reducing MAP (phase III), the magnitude dependent upon straining intensity [47] and body position [42]. The now elevated cardiac output is ejected against a constricted systemic circulation, a remnant of the vascular arm of the baroreflex response from preceding phases, transiently increasing MAP (phase IV) [42, 43, 48]. A more detailed account of the physiology of an isolated VM can be found elsewhere [41].

\section{Cerebrovascular Response to the Valsalva Manoeuvre}

As mentioned, CBF is regulated by a myriad of physiological variables, many of which undergo rapid and bidirectional perturbations during the $\mathrm{VM}$ alone. A hallmark of the VM is rapid changes in CPP, and although cerebral autoregulatory mechanisms are active, they are unable to effectively counter such changes [43, 49]. CPP is calculated by subtracting intracranial pressure (ICP) from MAP, and as ICP is elevated during a VM $[40,50]$, significant reductions in CPP can quickly ensue, particularly during phases IIa-IIb when MAP is reduced. The VM also elevates central venous pressure (CVP) [42], which restricts cerebral venous outflow, raises intracranial blood volume and subsequently ICP [51]. The increase in CVP may exceed that of CSF pressure and become the major determinant of ICP during the VM, with elevations in CVP reducing CBF $[52,53]$. Without an obvious VM, changes in intrathoracic pressure may persist during RE and alter cerebral venous drainage [54], particularly during axial loading of the spine as seen during upright squatting [55].

MAP increases during phase I, with no change $[47,56]$ or a modest increase $[42,57]$ in middle cerebral artery blood velocity (MCAv) reported. Furthermore, greater strains, despite producing greater hypertension, do not produce a greater increase in MCAv during phase 1 [47]. One proposed explanation is that ICP elevations mechanically restrain MCAv during phase I. Whilst the exact role of the autonomic nervous system in CBF control remains controversial [58], sympathetic vasoconstriction may have a similar function during high CPPs [59-61] and limit hyperperfusion. Comparatively, the phase IV response, associated with a normalisation of
ICP and rapid concurrent increases in MAP, produces a greater peak MCAv response than phase I [56]. In addition to phase IV reductions in ICP, functional hyperaemia contributes to the observed cerebral hyperperfusion [57], driven by an acute reduction in cerebral oxygenation during phase II (Fig. 2), compounded by an elevated $\mathrm{P}_{\mathrm{a}} \mathrm{CO}_{2}$ [42] and a cerebral autoregulatory vasodilation persisting from phase III [43].

It should be noted most of the data concerning the $\mathrm{VM}$, and data comprising this review, are from males (see Tables 1 and 2). This is problematic given that the phase IIb response to the VM is sex-dependent, with smaller increases in mean and diastolic MCAv observed in men [84]. Women also have a greater resting MCAv $[85,86]$ and differential cerebrovascular reactivity to $\mathrm{CO}_{2}$ [87, 88]. Additionally, cerebral autoregulation has been shown to be greater in the anterior cerebral artery [85] and MCA [89] vascular territories during acute hypotension in females, which persists irrespective of menstrual cycle phase [90]. As such, extrapolation of the discussed response to females is cautioned and further research is required to quantify the haemodynamic response to RE in females.

\section{Role of the Valsalva Manoeuvre During Resistance \\ Exercise}

During RE the VM acts to stabilise the trunk, providing a mechanical advantage $[39,91]$. However, the VM exacerbates the blood pressure perturbations during RE and is discouraged even in healthy adults [92]. For the advanced lifter, the manoeuvre is unavoidable at $\geq 80 \%$ of maximal voluntary contraction (MVC) or during repeated efforts when approaching fatigue [39]. As load increases the VM intensity, and therefore intrathoracic pressure, also increase [93] with more intense strains generating greater phase I MAP peaks [57]. The relative loading to specifically target power, strength, and hypertrophy may all exceed $80 \%$ of MVC during a training cycle [94]. As such, it is likely that resistance training individuals, irrespective of desired outcome, regularly perform a VM. During static RE with a VM, the haemodynamic profile is dominated by the VM [79], that is, all phases of the VM are discernible despite the background of sustained muscular contraction (Fig. 1). In contrast, as $\sim 15 \mathrm{~s}$ of straining is required to discern all phases of the VM $[42,95]$, the short strains experienced during dynamic RE are masked by the larger exercise dependent MAP fluctuations [55]. Indeed, peak strain intensity, as indicated by oesophageal pressure (surrogate for intrathoracic pressure), occurs during the transition from the eccentric to concentric phase during dynamic RE and aligns with peak blood pressures [96] (also see Fig. 3). Therefore, understanding the 


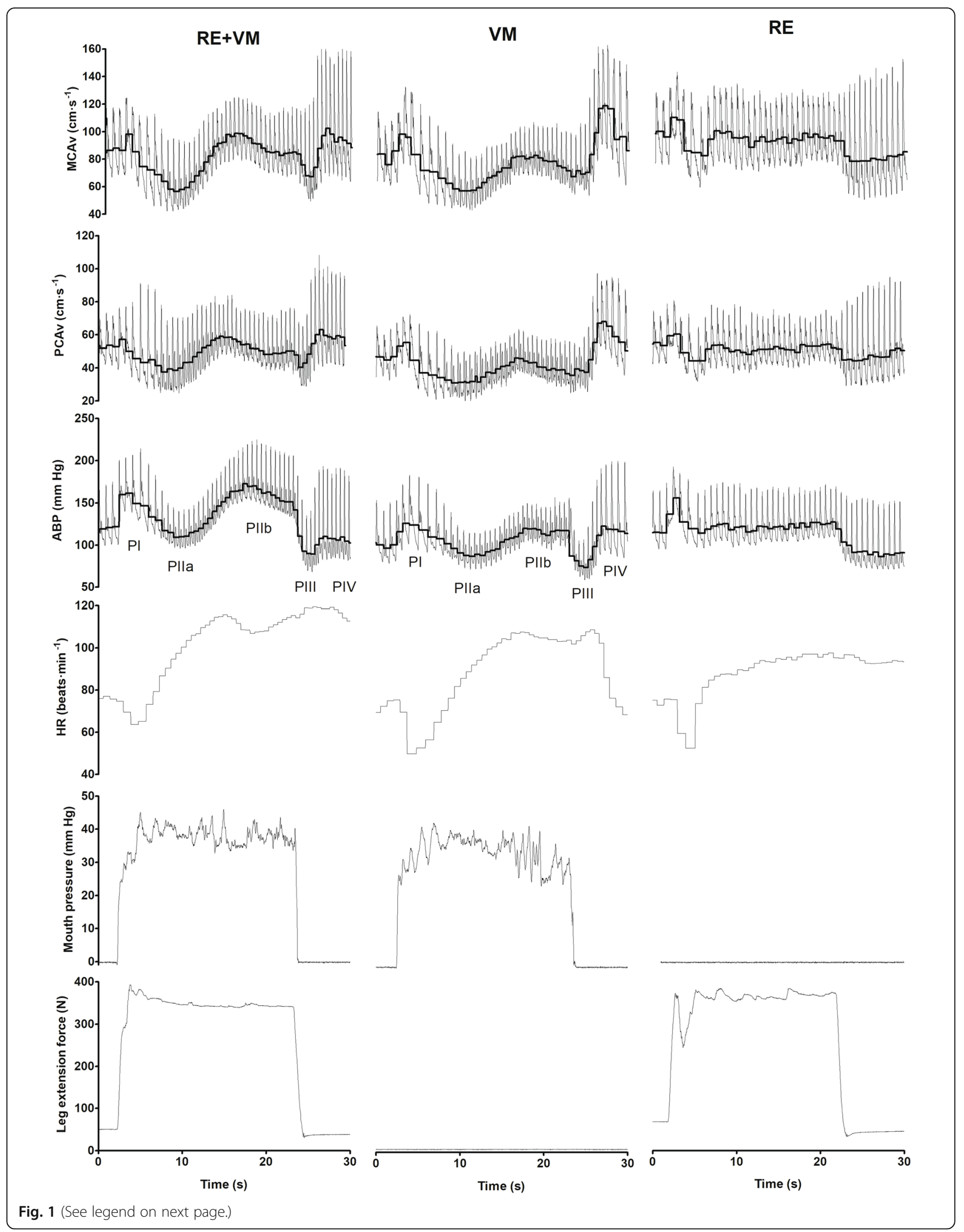


(See figure on previous page.)

Fig. 1 Typical trace for a combination of RE and VM (RE + VM), Valsalva manoeuvre (VM) in isolation, and isometric RE in isolation (RE). Phases of the VM (phase I (PI) through phase 4 (PIV)) are visible in both RE+VM and VM conditions. The thick black line in middle cerebral artery blood velocity (MCAv), posterior cerebral artery blood velocity (PCAv) and arterial blood pressure (ABP) traces represents the mean value for each cardiac cycle. HR heart rate. Reproduced with permission from [45]

haemodynamic profile during RE is dependent upon a complex interaction between $\mathrm{RE}$ type and VM recruitment.

\section{Physiological Response During Resistance Exercise Cardiovascular Response to Resistance Exercise Blood Pressure}

Despite the cerebral vasculature possessing welldeveloped autoregulatory mechanisms, the rate of change in CPP during dynamic RE provides a substantial challenge to blood flow regulation. The exact blood pressure response to RE is dependent upon contraction type and within the spectrum of RE, blood pressure responses vary greatly. Static RE produces modest, intensity dependent increases in blood pressure [97]. From contraction onset MAP steadily increases [98] to an eventual plateau, the beginning of which varies depending upon contraction time and intensity [79, 99, 100]. However, heavy dynamic RE produces extreme sinusoidal fluctuations in blood pressures (Fig. 3), with an individual peak of $480 / 350 \mathrm{~mm} \mathrm{Hg}$ (systolic/diastolic) reported and group average of $320 / 250 \mathrm{~mm} \mathrm{Hg}$ during dynamic bilateral leg press exercise [101]. Indeed, the extent of within-exercise hypertension is dictated by recruited muscle mass, with exercises utilising large muscle groups (e.g. leg press) generating the greatest hypertension [102-105]. Blood pressure responses are intensity dependent [105] and mediated by increases in both systolic and diastolic pressures [39, 106-108].

Within a dynamic movement, peak blood pressures are seen at the joint angle that corresponds with the weakest point of the strength curve [39, 109], which for leg press exercise corresponds with peak knee flexion [39] and generally coincides with the transition between eccentric and concentric contractions. Blood pressure declines as the concentric phase progresses [109] and the cycle repeats for each repetition (Fig. 3). Peak concentric blood pressure also increases in subsequent repetitions within a set $[96,101,105]$, in subsequent sets of the same exercise [107], or if the rest period between sets is reduced [110]. Sale et al. [96] investigated the blood pressure response to bilateral leg press during various contraction types (concentric, isometric, and eccentric) using an isokinetic dynamometer and reported that irrespective of contraction type, the primary determinant of blood pressure was the voluntary effort, determined by force output rather than measurement of perceived exertion. Nevertheless, intense multi-joint efforts will evoke the greatest within-exercise blood pressure. Therefore, under the term RE, it is possible to generate disparate blood pressure profiles, dependent upon the type of contraction; i.e. static RE produces a relatively slow developing and modest increase in MAP that plateaus, whereas cyclic swings in blood pressure typify dynamic RE.

\section{Cardiac Output}

In comparison to the classification of blood pressure during RE, a paucity of cardiac output data is available, which is problematic for the description of CBF regulation given cardiac output modulates CBF independently of blood pressure [22]. During high-intensity leg press exercise (95\% 1RM), SV is reduced and elevations in cardiac output are driven primarily by HR [109], with similar results found during static handgrip exercise [99, $111,112]$. However, this is not a consistent finding for isometric exercise during static leg extension with [79], and without [113], the VM. It would be expected that the VM would inhibit venous return such that HR does not compensate for the reduction in SV [79]. In contrast, unloaded upright squatting exercise increases preload and cardiac output [114, 115], and it should be noted dynamic contractions would facilitate venous return due to the skeletal muscle pump. As MAP undergoes cyclic changes throughout a single repetition, primary determinants of SV, such as afterload and preload will also change dynamically. Indeed, phase-dependent changes in cardiac output have been reported previously, with increases demonstrated throughout leg press exercise, peaking at the end of the concentric phase driven by a recovery of SV [109]. Nevertheless, during muscle contraction, irrespective of type, the prime driver for an increase in cardiac output appears to be heart rate.

\section{Cerebral Blood Flow Regulation During Resistance Exercise}

As mentioned above, regulation of CBF is complex with stringent processes to ensure adequate perfusion, and ultimately, maintenance of function [116]. Exercise, of any nature, can challenge $\mathrm{CBF}$ regulatory mechanisms as multiple determinants of CBF may exert their effects simultaneously. Recently, Smith and Ainslie [30] have suggested that the current literature is unable to clearly identify the individual roles and contributions of all regulatory variables to the observed $\mathrm{CBF}$ responses and is indicative of the intricate-dependent relationship 

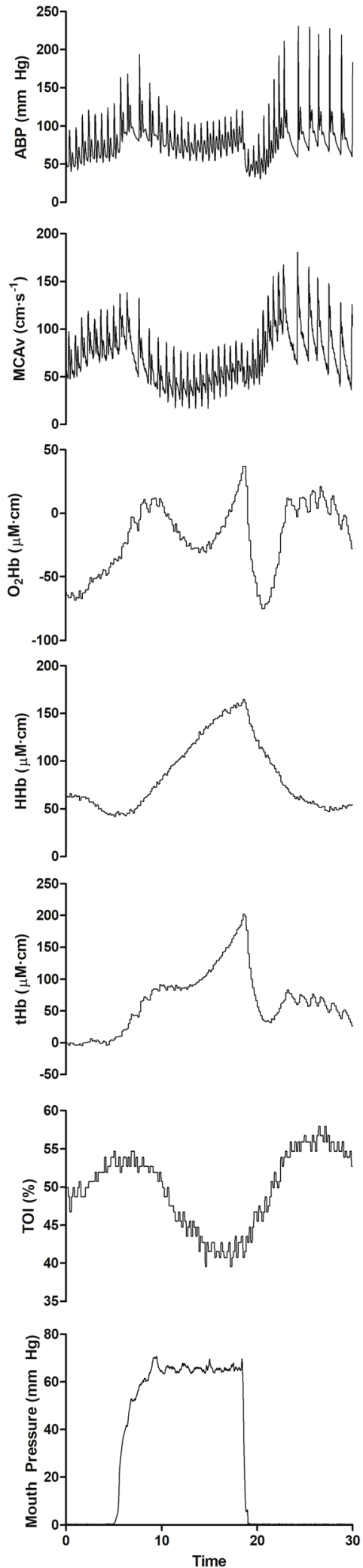

Fig. 2 Hemodynamic variables in one participant during a Valsalva manoeuvre at $90 \%$ of maximal mouth pressure for $10 \mathrm{~s}$. ABP arterial blood pressure; $M C A v_{\text {mean }}$ mean middle cerebral artery blood velocity; $\mathrm{TOl}$ total oxygenation index; $\mathrm{O}_{2} \mathrm{Hb}$ oxyhaemoglobin; $\mathrm{HHb}$ deoxyhaemoglobin; tHb total haemoglobin. Reproduced with permission from [57]

many variables demonstrate (e.g. $\mathrm{P}_{\mathrm{a}} \mathrm{CO}_{2}$ and MAP). The majority of studies investigating the cerebrovascular response to exercise have utilised steady-state aerobic exercise, in particular upright or semi recumbent cycling [22, 117-126]. Even within the general classification of dynamic aerobic exercise some modalities, like rowing, demonstrate a markedly different CBF profile from cycling, with clear influence of blood pressure in the former. Indeed, during rowing MCAv profiles similar to dynamic RE are observed, sinusoidal, and often commensurate with blood pressure $[127,128]$. The inherent complexity of $\mathrm{CBF}$ regulation is compounded by the VM and associated mechanical effects of perturbations in ICP during RE and rowing. Similarly, running produces rhythmic oscillations in blood pressure and MCAv [129], produced by interference between stride frequency and heart rate [130]. Whilst the hierarchy of cerebrovascular regulators still exists during $\mathrm{RE}$ (i.e. $\mathrm{P}_{\mathrm{a}} \mathrm{CO}_{2}$ is the most potent [65]), it is evident that the cerebrovascular response is not uniform between exercise types. For instance, cardiac output contributes to MCAv elevations more during cycling than during rhythmic hand grip exercise [73]. Therefore, knowledge of cerebrovascular function during aerobic exercise cannot be extrapolated to RE.

Moreover, the different blood flow profiles between exercise modalities, including the various types of $\mathrm{RE}$ outlined within this review, may elicit different adaptive processes during habitual exposure (i.e. training). A key mechanism for exercise-related improvements in vascular function is attributed to the frictional forces that result from the mechanical movement of blood across the vascular endothelium (i.e. shear stress [131]). As outlined below, RE can provoke a wide range of blood flow responses during and following a bout, the consequences of which related to improved or impaired vascular function are largely unknown.

\section{Dynamic RE}

During RE a fourfold increase in arterial blood pressure during the concentric phase of lifting has been reported [101], greatly exceeding the traditionally proposed upper autoregulatory limit [31]. During high intensity cycling exercise dynamic cerebral autoregulation is active and able to effectively modulate CBF [126, 132, 133]; however, given the rapid nature of the fluctuations in blood pressure during dynamic RE, cerebral autoregulation is 


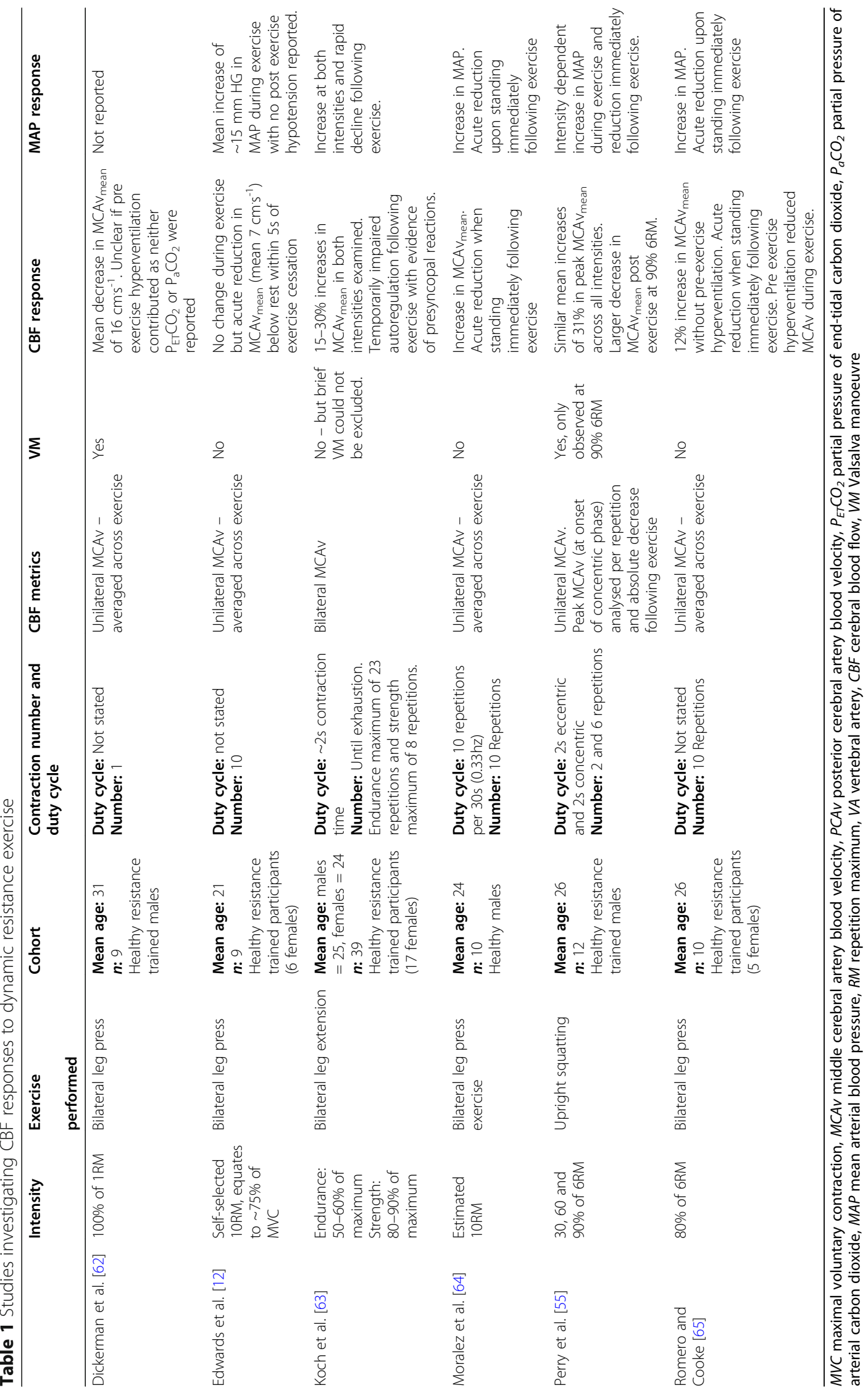




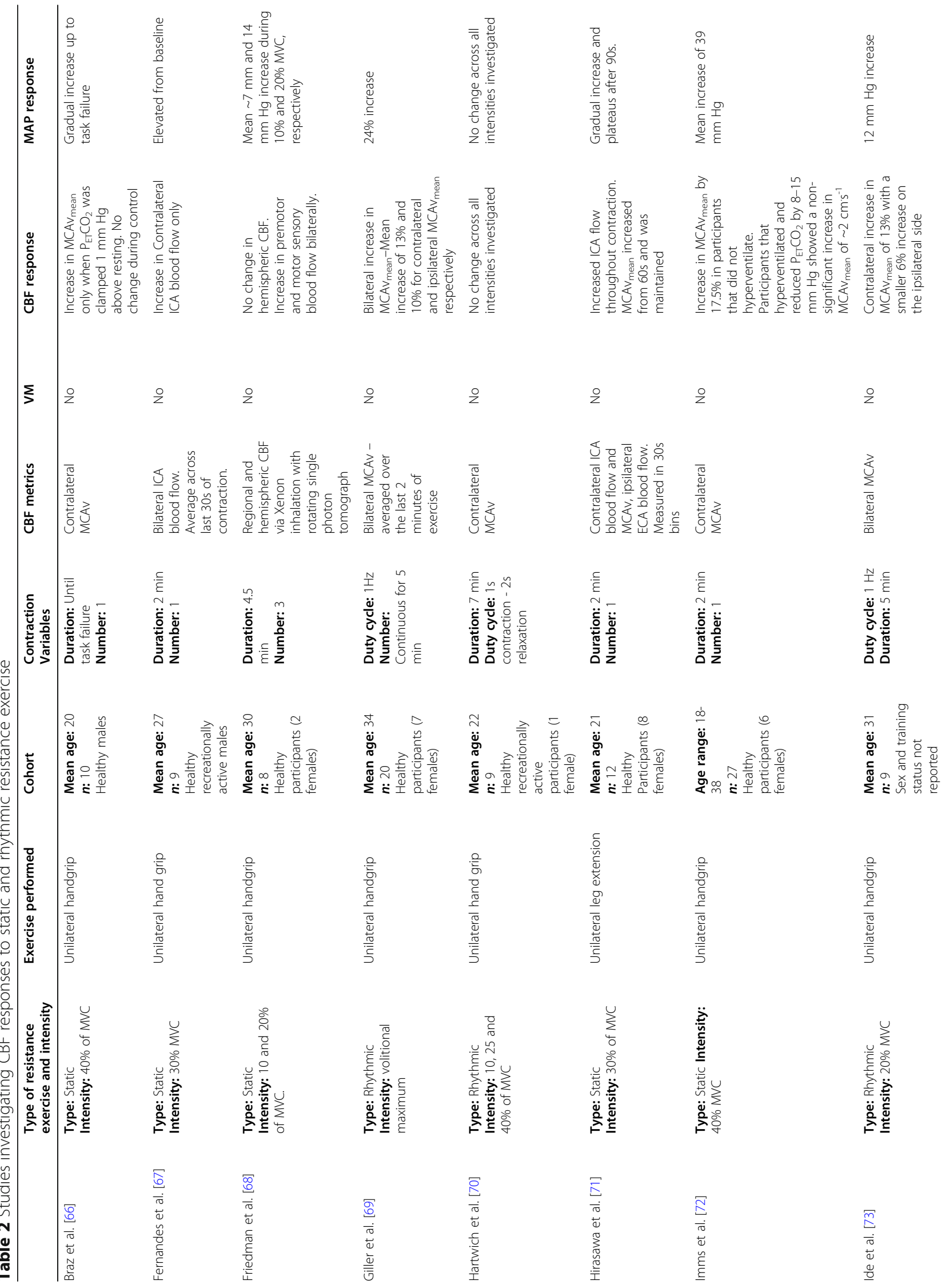




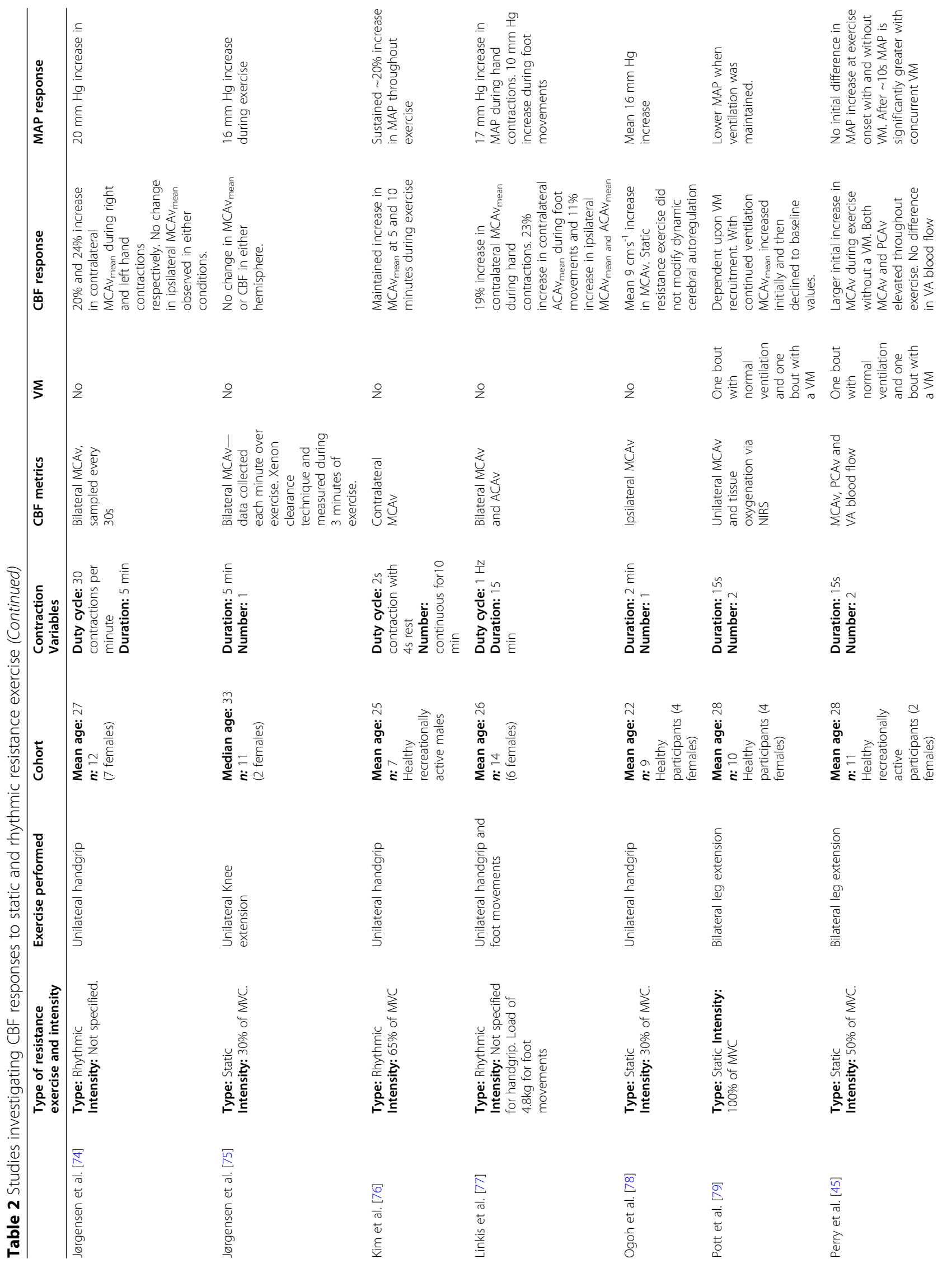




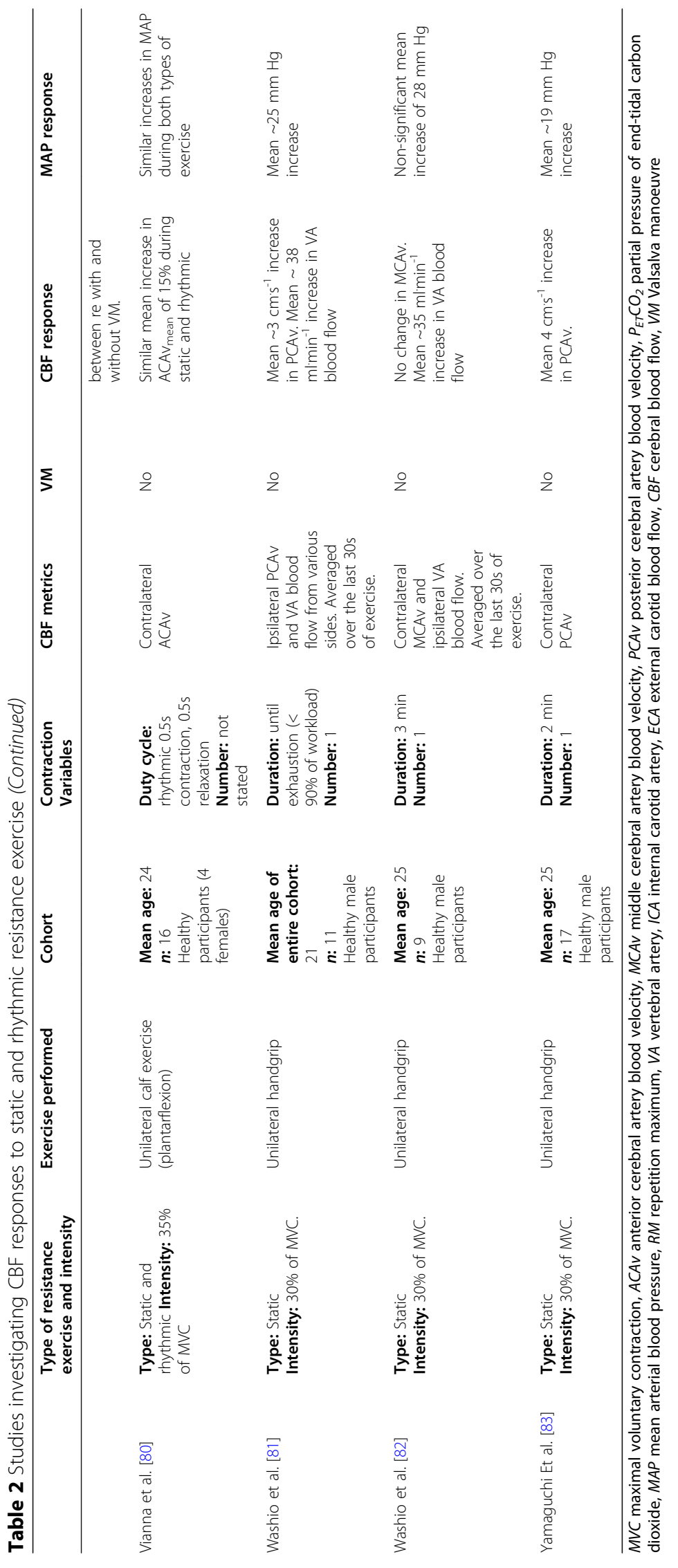




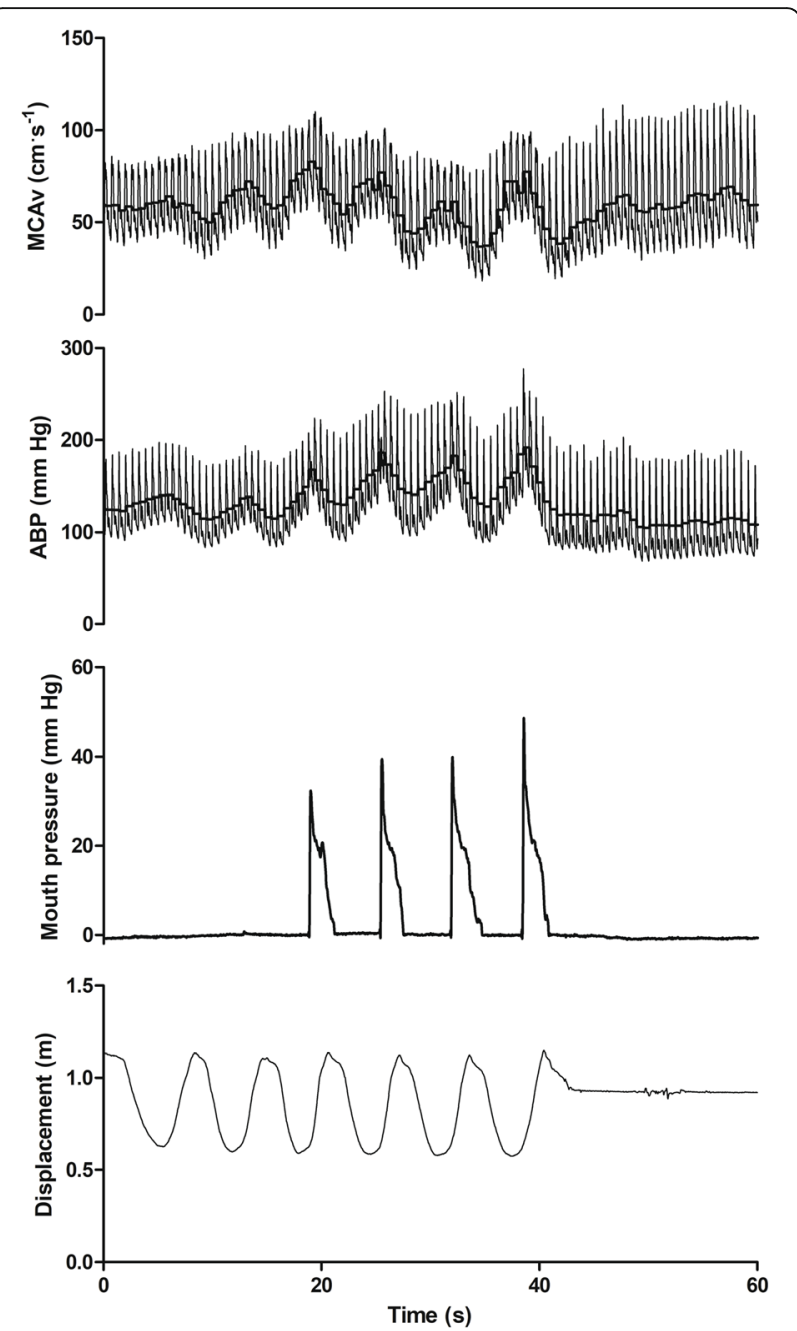

Fig. 3 Haemodynamic response to 6 upright squats at $60 \%$ of one repetition maximum. MCAv middle cerebral artery blood velocity; ABP arterial blood pressure. The thick black line in the MCAv and ABP traces represents the mean for each cardiac cycle. Note that a reduction in displacement indicates the eccentric phase of the squat. A VM was only performed on the last 4 repetitions of the set, noting the resultant increase in MAP. Peak VM pressure occurs at the transition from eccentric to concentric contraction and coincides with peak blood pressure. Data from Perry et al. [55]

likely insufficient, such that MCAv varies commensurate with MAP [12, 65] as is observed during leg press [12] and squatting with additional load [55]. As impressive as the peak blood pressures appear, several authors indicate that $\triangle$ MAP dictates the cerebrovascular response $[12$, 63], illustrating the high-pass filter [134] characteristics of the cerebral circulation and reflecting the inherent latency ( $\sim 5 \mathrm{~s})$ of autoregulatory mechanisms [135]. The variation of MCAv with MAP persists during within-exercise hypertension, despite hysteresis [136-138]. Evidently, repeated body weight squatting manoeuvres have been used to perturb MAP and assess dynamic cerebral autoregulation $[138,139]$.
Habitual RE reduces central arterial compliance [140] and we have previously speculated that the cerebral circulation is not excluded from such adaptations. As cerebrovascular compliance modulates cerebral autoregulation [141], it is plausible that repeated hypertensive stimuli may modify autoregulatory function. We have shown that despite the substantial differences between exercise types, aerobically trained individuals (excluding rowing) and resistance trained individuals demonstrate similar dynamic autoregulatory capacity during forced MAP oscillations (repeated squat stands) [142]. However, we did demonstrate a trend for transfer function derived gain to be greater during slower frequency $(0.05 \mathrm{~Hz})$ oscillations in MAP in the resistance trained cohort. Moreover, resistance trained individuals demonstrate higher MCA pulsatility at rest [143], likely due to the reduction in pulsatile buffering capacity of the central arteries. These data indicate subtle modifications in cerebrovascular function; however, given the plasticity of cerebral autoregulation [144], it is possible that improved function in resistance trained individuals may be revealed at high perfusion pressures and/or possess a greater effective autoregulatory range.

Reports to date on the $\mathrm{MCAv}_{\text {mean }}$ response during dynamic RE (all exercises) are equivocal, with some reporting increases [63-65, 70,76], no change [12] or a decrease [62]. Studies utilising leg press RE have reported all possibilities. It should also be considered that a simple average over the course of dynamic RE does not reflect the MCAv profile during exercise, as highlighted in Fig. 3. If leg press exercise is considered, studies that demonstrated an increase $[64,65]$ or no change [12] in $M C A v_{\text {mean }}$ during exercise did not use a $\mathrm{VM}$, but did use $80-100 \%$ of 10 repetition maximum. However, as the VM is recruited $\geq 80 \%$ of MVC or during repeated efforts when approaching fatigue [39], it is unlikely that the load used is a true reflection of the $80-100 \% 10$ repetition maximum. In contrast, Dickerman et al. [62] reported that during a onerepetition maximum leg press exercise bout in elite level resistance trained individuals, the VM was responsible for a $25 \%$ reduction in $\mathrm{MCAv}_{\text {mean }}$. However, these authors did not report $\mathrm{P}_{\mathrm{a}} \mathrm{CO}_{2}$ (or partial pressure of end tidal $\mathrm{CO}_{2}\left(\mathrm{P}_{\mathrm{ET}} \mathrm{CO}_{2}\right)$ as a proxy). Similar to rest, $\mathrm{P}_{\mathrm{a}} \mathrm{CO}_{2}$ exhibits a strong influence on CBF during RE [66], which is important given the typical pre-exercise breathing patterns during high intensity lifts comprises of hyperventilation [15], followed by an intense VM. Indeed, pre-exercise hyperventilation that reduced $\mathrm{P}_{\mathrm{ET}} \mathrm{CO}_{2}$ by $\sim 8 \mathrm{~mm} \mathrm{Hg}$ (absolute value $=26 \mathrm{~mm} \mathrm{Hg}$ ) lowered exercise (leg press at $80 \%$ of $6 \mathrm{RM}$ ) $\mathrm{MCA}_{\text {mean }}$ by $\sim 39 \%$ without a concurrent VM [65]. It is also worth noting that hypocapnia improves dynamic cerebral 
autoregulation [19]. Hyperventilation therefore may serve a complex role during RE, namely: (1) act as a preexercise routine, (2) reduce the absolute CBF (hyperperfusion) during RE, and (3) improve autoregulation such that changes in CPP are more adequately buffered.

In addition to hyperventilation the VM may also protect the cerebral vasculature during exercise via a reduction in transmural pressure [50]. The VM generates additional increases in MAP, and whilst initially this would appear detrimental, we have reported that peak $\mathrm{MCAv}_{\text {mean }}$ was similar between $90 \%, 60 \%$, and $30 \%$ of $6 \mathrm{RM}$, despite the greatest increase in MAP observed for the $90 \%$ set, with the VM only recruited at this intensity [55]. At the transition point between eccentric and concentric contraction, when VM recruitment is permissible, the greatest oesophageal pressures are observed, which subsequently decline as the concentric phase progresses in a remarkably similar fashion to MAP [96, 109]. As the VM is unavoidable at intensities $\geq 80 \%$ of MVC [39], it is plausible that participants self-select the VM strain intensity [intrathoracic pressure] to match exercise intensity, and therefore blood pressure; evident as when participants approach fatigue, which is associated with greater voluntary efforts, both MAP and strain intensity rise [96, 109]. Whilst speculative, this inherent VM self-selection intensity could culminate in proportionate increases in ICP, limiting CBF during peak CPP and mitigating drastic perturbations in cerebrovascular transmural pressure. As thoracic pressure and MAP decrease concurrently throughout the concentric phase, CPP is stabilised as both ICP and MAP would fall concurrently, maintaining CBF. Taken together, the anticipatory hypocapnia and use of the VM modify the CBFblood pressure relationship during $\mathrm{RE}$ with the latter potentially providing a temporary protective mechanism.

\section{Static Resistance Exercise}

During static RE (hand grip and knee extension), increases in $\mathrm{MCAv}_{\text {mean }}[22,71,72,74,76,79]$, internal carotid artery $[67,71]$ and vertebral artery [81, 82] blood flow have been reported. However, some authors have reported no change in $\mathrm{MCAv}_{\text {mean }}$ during static hand grip [66] or leg extension [75]. Similarly to dynamic RE, $M C A v_{\text {mean }}$ is dependent upon the ventilatory response and subsequently $\mathrm{P}_{\mathrm{a}} \mathrm{CO}_{2}$, with pre- [145] and within[72] exercise hyperventilation lowering exercise and recovery $\mathrm{MCAv}_{\text {mean. }}$ Braz et al. [66] reported that during static hand grip exercise, $\mathrm{MCAv}_{\text {mean }}$ elevations were evident only when $\mathrm{P}_{\mathrm{ET}} \mathrm{CO}_{2}$ was clamped $1 \mathrm{~mm} \mathrm{Hg}$ above resting. Therefore, discrepancies may result from an overriding influence of hypocanpic vasoconstriction and corroborate findings in dynamic RE.

Dynamic cerebral autoregulation has been reported to be unaffected during and following static [78] and rhythmic handgrip [76] exercise. Static RE is associated with a prolonged pressor response with a plateau in MAP [45, 71, 79]. Hirasawa et al. [71] reported a plateau in ICA flow $60 \mathrm{~s}$ into a 120-s unilateral static leg contraction at $30 \%$ of MVC. External carotid artery blood flow, however, demonstrated a continual rise, concurrent with small increases in MAP in the later stages, indicative of a potentially protective mechanism by directing flow extracranially during hypertension [83]. Whether this persists during dynamic exercise with larger increases in MAP is unknown, and difficult to assess with current imaging methodologies (see Measurement challenges and considerations). Using maximal static bilateral leg extension (without VM), Pott [79] reported a sharp increase in MCAv $\left(\sim 10 \mathrm{~cm}^{-1}\right)$, peaking at $\sim 3 \mathrm{~s}$ but returning to baseline by $\sim 5 \mathrm{~s}$. Moderate increases in PCAv $\left(\sim 6 \mathrm{~cm} \mathrm{~s}^{-1}\right)$ have also been shown in static handgrip exercise at $30 \%$ of MVC [146]. Further studies that did not report a time effect have also reported increases in MCAv [78], PCAv [81], ICA [67] and VA flow [81]. Interestingly, we have shown larger initial (time aligned with VM phase I) increases in MCAv, but not for PCAv, during $\mathrm{RE}$ with normal ventilation compared to exercise with the VM [45]. However, these effects diminished with contraction time such that no differences were observed after $\sim 12 \mathrm{~s}$, likely reflecting the engagement of cerebral autoregulation after $>5 \mathrm{~s}$ such that blood velocity is stabilised [135].

It should also be considered that during single limb exercise the alterations in blood flow to the brain are heterogeneous. Firstly, when considering cerebrovascular autoregulation some [147, 148], but not all [149], report regional differences in blood flow responses to blood pressure perturbations. Similarly, cerebrovascular reactivity to $\mathrm{CO}_{2}[150,151]$ may differ between the posterior and anterior circulations, although this is not a universal finding during hypercapnia [21]. Secondly, more pronounced elevations in blood flow are observed in vessels contralateral to the exercising limb due to the anatomical location of motor areas within the brain, evident during unilateral RE. For example, Linkis et al. [77] reported that right hand contractions produced a $19 \%$ increase in contralateral MCAv with no change in ipsilateral MCAv. Increases in blood flow to premotor and motor sensory areas have been reported during lowintensity static handgrip [68] and leg extension [152], with no change in global hemispheric flow as measured using the xenon clearance technique. Increase in blood flow is mediated by NVC and has been observed in the contralateral ICA [67] and VA [81], and supported by increases in MCAv [70,73] during unilateral static exercise. Ipsilateral ICA blood flow appears to be restrained by sympathetic vasoconstriction during unilateral hand grip exercise [67]. In support of autonomic regulation 
during RE, intracranial arteries such as the MCA undergo sympathetic vasoconstriction during rhythmic hand grip exercise [59]. Importantly, the blood flow response in the contralateral hemisphere is dependent upon volitional contractions (central command) as passive rhythmic exercise and electrically stimulated exercise do not alter blood velocity in the anterior cerebral artery [80]. Due to the slow and progressive increase in MAP during static RE without a VM the effect of NVC can be observed, in contrast to dynamic RE where this response is masked by rapid changes in CPP. Irrespective of the nature of contraction, the increase in CPP may exacerbate NVC mediated increases in cerebral perfusion. Whilst the exact role of the autonomic nervous system during RE is yet to be elucidated, the primary driving factor of CBF during dynamic RE appears to be CPP; conversely, during low-intensity static contractions NVC are likely the primary driver. It appears that the slow progressive increases in CPP during static RE can be effectively countered by cerebral autoregulation. Therefore, application of findings in small muscle groups utilising static contractions to all types of RE should be done with caution.

\section{Physiological Response Following Resistance Exercise}

Blood pressure immediately following resistance exercise Reductions in mean, systolic, and diastolic blood pressures have been consistently reported immediately (within seconds) following $\operatorname{RE}[15,64,65,153-155]$, with an increase in pressure pulsatility [156]. During muscle contraction blood flow is inhibited, with increases in intramuscular pressures occluding arterial and/or venous blood flow [157]. Following exercise, however, blood flow to active musculature increases [158] mediated by metabolic dilation; a functional hyperaemia $[159,160]$ that is aided by a reduction in transmural pressure during relaxation [161]. Hyperaemia following lower limb exercise is exacerbated in the upright position [162] and is dependent on contraction intensity [163] and frequency [164]. In support of this, we have previously observed a load dependent hypotension immediately following upright squatting with the greatest relative intensity producing lower absolute blood pressures [55]. Moreover, MAP time to recovery and time below baseline were greater, mediated by acute reductions in cardiac output and total peripheral resistance, with similar results observed following upright static deadlifting [165]. To date, studies investigating the haemodynamic response to RE have typically utilised a legpress type movement $[12,64,65]$, static/isometric type exercise $[78,103]$ or both $[96,102]$. The legpress position facilitates venous drainage, as the feet are at or above heart level, such that hypotension is not observed when participants remain semirecumbent [12]. Thus, the upright position in combination with greater exercise intensities exacerbates the transient post-exercise hypotension irrespective of contraction type. Similarities of post exercise hypotension following RE can occur with initial orthostatic intolerance, with the latter characterised by venous pooling [166], and reductions in venous pressure [167] and total peripheral resistance [168]; this culminates in a rapid translocation of the blood into the limbs with the abrupt reduction in MAP exceeding the baroreflex control of vascular tone [169]. Considering these mechanisms in the context of post RE hypotension, it is likely that functional hyperaemia to musculature below heart level and the rapid reduction in intramuscular pressure would exacerbate these responses in an intensity dependent manner.

\section{Cerebrovascular Response Following Resistance Exercise}

Cerebral hypoperfusion sufficient to induce syncope has been reported immediately following RE [15] and is likely driven by the hypotension described above. However, pre-exercise hyperventilation lowers pre- and within-RE MCAv [65] likely increasing the risk of postexercise syncope. Despite hypocapnia improving autoregulatory capacity, the speed of hypotension onset outpaces the reflex cardiovascular and cerebrovascular countermeasures such that decrements in CBF persist. In the absence of $\mathrm{P}_{\mathrm{a}} \mathrm{CO}_{2}$ perturbations, cerebral autoregulatory phase is reduced immediately following dynamic RE, indicating an impaired regulatory capacity [63]. The magnitude of CBF reduction is dependent upon the load lifted when upright and closely aligns with the MAP pattern following exercise cessation, with the largest, and most prolonged, decrease in MCAv observed after lifting the highest relative load [55]. Importantly, the highest relative load coincided with the recruitment of the VM, the implications of which are discussed in the following section. Without the presence of hypotension, MCAv declines below baseline following lower limb RE when in a semi-recumbent position emphasising that $\triangle \mathrm{MAP}$, not absolute MAP, drives the CBF response [12]. Notwithstanding, recent evidence indicates dynamic autoregulation is modified by body position with reduced function during standing [86], compounding the effect of greater hypotension following upright exercise. Of note, the decrement in MCAv following exercise is primarily due to reductions in diastolic blood velocity [55], similar to pre-syncope [170]. However, the increase in pulsatility is acute, with normalisation apparent 10 min following exercise cessation [156]. As with the responses during exercise, the post RE cerebrovascular responses still appear to be 
dominated by the rapidly changing CPP. Whilst hypotension is not always observed following RE due to body position, hypotension is associated with greater reductions in cerebral perfusion and the recruitment of the VM.

\section{The Role of the Valsalva Manoeuvre Following Resistance Exercise}

The role of the VM during RE is complex (Fig. 4), with phase-dependent effects apparent. As mentioned previously, the effect of this VM may limit cerebral perfusion during exercise and be viewed as beneficial; however, following exercise, the detrimental circulatory effects of the VM are apparent. Short duration VMs $(\sim 10 s)$ in isolation produce phase II reductions in cerebral oxygenation (Fig. 2) [57], sufficient to induce syncope when standing [47]. Therefore, it is not surprising that syncope is has been reported following upright high intensity RE when the VM is recruited [15]. In the upright position, the combination of the release of the strain, exerciseinduced functional hyperaemia to the dependent musculature below heart level (e.g. during Olympic style lifts, squatting or deadlifts), and pre-exercise hyperventilation threaten maintenance of $\mathrm{CBF}$ following $\operatorname{RE}[55,65]$. Whilst pre- and within-exercise hyperventilation likely contribute to post-exercise cerebral hypoperfusion, the rapid reduction in CPP likely underpins post exercise syncope, as pre-straining hyperventilation is not present in syncope following even short VMs [47]. As VM-phase III hypotension and MCAv reductions are less when supine [42] or seated (Fig. 1), the likelihood of postexercise syncope is likely mitigated in these positions.
Residual cerebral vasoconstriction, mediated by hypocapnia, cerebral autoregulation, or both, likely persists following exercise due to inherent latency of cerebrovascular reactivity to $\mathrm{CO}_{2}$ [171] and autoregulation [135]. As such, CPP may rapidly decline whilst the cerebral vasculature is constricted, although this would depend on the length and timing of the release of the strain. Long straining periods, like those observed in complex, multi-phase lifts (Olympic style lifting) [15], likely exacerbate the issue, as cerebral perfusion is depressed for longer periods and oxygenation compromised. Therefore, the effects of body position and the VM act in concert to compound the haemodynamic stress immediately following RE. Other interactive possibilities also exist during dynamic $\mathrm{RE}$ and require further investigation-for example (1) a single VM may span several repetitions, and (2) the timing of a brief VM may generate a scenario where the release of the breath hold during late phase I (MAP declining) coincides with the cessation of exercise and associated functional hyperaemia, such that a rapid decline in MAP ensues despite a short straining period.

Hitherto, we have focused on the most common postexercise clinical presentation-syncope. Whilst syncope is the obvious adverse post-exercise event, a greater potential issue is the prevailing cerebral hyperperfusion. With the VM alone, we have previously reported a near three-fold increase in phase IV MCAv from baseline, where the greatest peak in MCAv was achieved (see Fig. 2 for across phase comparison) [47]. During static RE, this response persists (Fig. 1), with greater peak blood velocities $>3 \mathrm{~s}$ after exercise associated with

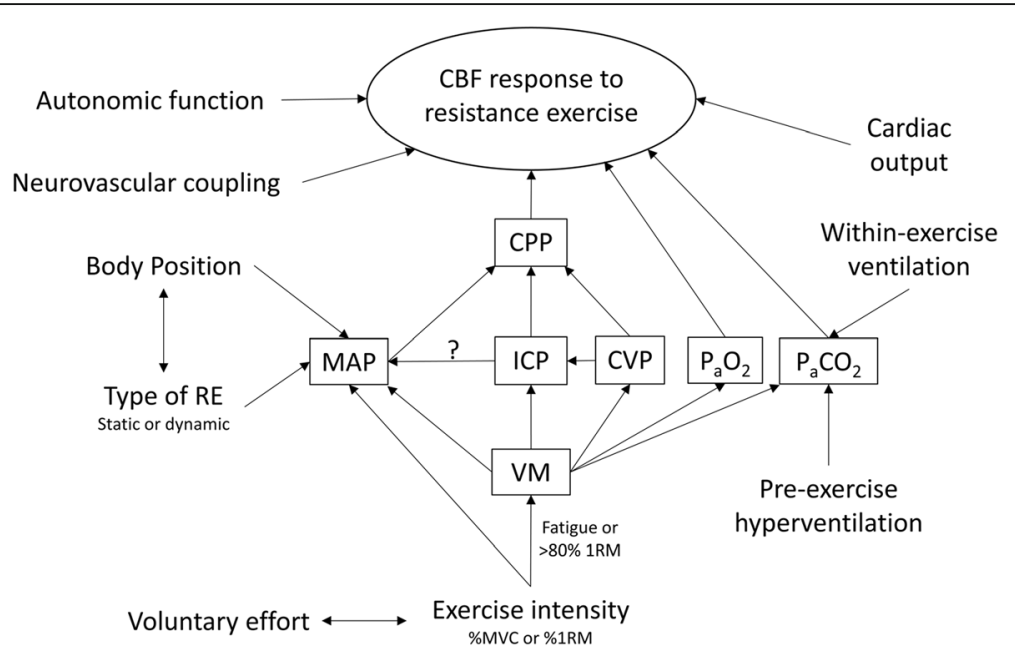

Fig. 4 Summary of the physiological regulators of cerebral blood flow (CBF) during RE. RE resistance exercise, CPP cerebral perfusion pressure, MAP mean arterial blood pressure, ICP intracranial pressure, CVP central venous pressure, $\mathrm{P}_{\mathrm{a}} \mathrm{CO}_{2}$ the partial pressure of arterial carbon dioxide, $\mathrm{P}_{\mathrm{a}} \mathrm{O}_{2}$ the partial pressure of arterial oxygen, VM Valsalva manoeuvre, MVC maximal voluntary contraction and 1RM one repetition maximum 
elevated pulsatility in the PCA and MCA [45]. Similarly, seconds following dynamic RE with a VM, rapid increases in cerebrovascular conductance and MCAv are evident [55]. Further investigation is required to quantify the acute and long-term implications of repeated VMs during RE to inform safe practice, although several methodological challenges must be overcome first.

\section{Measurement Challenges and Considerations}

Investigating RE presents many challenges, primarily methodological limitations that include measurement of blood pressure. Non-invasive (e.g. finger photoplethysmography) and direct arterial measurement [101] of blood pressure require one hand to be free and resting, limiting the scope of exercise to either lower limb, or unilateral upper limb RE. Thus, appropriate bilateral blood pressure comparisons between upper and lower limb exercise are missing which inhibits exploring potential differences in CBF-blood pressure relationships between different exercises and/or muscle groups. Another inhibitor of physiological measurement is the physical movement of the participant during RE, limiting most research to static RE. Given the majority of RE performed [94] and recommended [10, 92, 172, 173] is of the dynamic variety, issues arise with extrapolating findings to all variants of RE. However, the greatest challenge is measuring CBF, as discussed below.

The accuracy of transcranial Doppler has recently been questioned $[69,174]$ during large changes in blood pressure [59] and $\mathrm{P}_{\mathrm{a}} \mathrm{CO}_{2}[88,175,176]$, conditions that typify RE. Inferences of blood flow from velocity should be made with caution [174] as the use of transcranial Doppler ultrasound as a surrogate for blood flow requires a stable arterial diameter. Using magnetic resonance imaging, rhythmic handgrip exercise (60\% MVC) produced a $2 \%$ decrease in contralateral MCA surface area, suggested to be a direct result of sympathetic vasoconstriction [59]. As changes in MCA diameter occur during moderate intensity exercise with a small unilateral muscle mass (hand grip exercise), the constancy of intracranial arterial diameter during RE (dynamic or static) with a large muscle mass cannot be assumed. Additionally, during transient hypotension blood velocity recordings may underestimate flow, particularly in the posterior circulation [149]. Further investigations are required to establish whether sympathetically mediated vasoconstriction persists at high-intensity dynamic RE or if cerebral arteries are passively dilated by the extreme intramural pressure (MAP $>300 \mathrm{~mm} \mathrm{Hg}$ ) [101]. As such, the data utilising transcranial Doppler must be interpreted with caution.

Given the uncertainty surrounding the constancy of intracranial arterial diameter, researchers commonly use duplex ultrasound to measure blood flow in upstream extracranial feed arteries to corroborate transcranial Doppler data [177]. However, participant movement largely excludes this technique and others (e.g. magnetic resonance imaging) during dynamic RE. Moreover, temporal resolution sufficient to capture beat-to-beat flow is required to encapsulate the dynamic nature of the haemodynamic profile of RE. Imaging transcranial doppler devices could provide a solution; however, measurement of intracranial vessel diameter remains an issue [178]. In addition to complicating the haemodynamic profile, the VM complicates the measurements of CBF and is largely avoided [12, 63-65, 67, 78, 81] (Tables 1 and 2). During the VM, the internal jugular vein fills with blood, obfuscating the common carotid artery and its bifurcations, limiting the measurement of blood flow to the vertebral arteries. Whilst possible to obtain ICA blood flow during a VM, longer VMs are required $(>30$ s), increasing the likelihood of adverse advents (e.g. syncope) and reducing applicability. Nevertheless, ongoing investigations into cerebrovascular control during RE with a concomitant VM are pertinent, as persons training at high intensities, or to near fatigue, will likely utilise the VM. The anatomy of the brain and skull remains an issue for the researcher, particularly when quantifying CBF. These issues are not new [179]; however, they preclude the accurate measurement of intracranial blood flow with sufficient temporal resolution and accuracy to reveal a more comprehensive understanding of $\mathrm{CBF}$ regulation during RE.

\section{Conclusions}

Under the blanket term of exercise disparate blood pressure and CBF responses exist. Further, within RE alone, the type of contraction generates markedly different CBF responses. Given these clear differences, it is plausible to expect the relative contributions of regulatory mechanisms to the observed CBF response to differ in contribution between types of exercise, and the findings from one type cannot be applied ubiquitously. It appears that the hierarchy of $\mathrm{CBF}$ regulation still exists during $\mathrm{RE}$, with $\mathrm{P}_{\mathrm{a}} \mathrm{CO}_{2}$ dominant. However, sinusoidal perturbations in MAP produced by dynamic RE and the inclusion of the VM profoundly challenge cerebrovascular regulation, with the latter dominant during a background of static RE. Further research is required, particularly during dynamic resistance exercise, to (1) elucidate the contribution of the VM to CBF regulation, (2) quantify the role of the sympathetic nervous system, (3) establish more accurate means of measuring CBF during large changes in MAP, and (4) establish the chronic cerebrovascular adaptations to RE. The effectiveness of RE cannot be ignored; however, a more complete understanding of haemodynamic responses is required to inform safe practice. 


\section{Acknowledgements}

The authors thank the researchers for their contribution to the field.

\section{Code availability}

$\mathrm{N} / \mathrm{A}$

\section{Authors' contributions}

BGP generated the idea for the article and drafted the review. Both authors edited the article and approved the final version of the manuscript

\section{Funding}

No funding was received for the review.

\section{Availability of data and materials}

Data sharing not applicable to this article as no datasets were generated or analysed during the current study.

\section{Declarations}

\section{Ethics approval and consent to participate}

N/A

\section{Consent for publication}

\section{Competing interests}

The authors, Blake Perry and Samuel Lucas, declare that they have no competing interests.

\section{Author details}

'School of Health Sciences, Massey University, Wellington, New Zealand. ${ }^{2}$ School of Sport, Exercise and Rehabilitation Sciences \& Centre for Human Brain Health, College of Life and Environmental Sciences, University of Birmingham, Birmingham, UK.

\section{Received: 24 November 2020 Accepted: 7 March 2021}

\section{Published online: 27 May 2021}

\section{References}

1. Kraemer WJ, Deschenes MR, Fleck SJ. Physiological adaptations to resistance exercise. Sports Med. 1988;6(4):246-56

2. Landi F, Marzetti E, Martone AM, Bernabei R, Onder G. Exercise as a remedy for sarcopenia. Curr Opin Clin Nutr Metab Care. 2014;17(1):25-31.

3. Villareal DT, Aguirre L, Gurney AB, Waters DL, Sinacore DR, Colombo E, et al. Aerobic or resistance exercise, or both, in dieting obese older adults. $\mathrm{N}$ Engl J Med. 2017;376(20):1943-55.

4. Mattson MP, Maudsley S, Martin B. BDNF and 5-HT: a dynamic duo in agerelated neuronal plasticity and neurodegenerative disorders. Trends Neurosci. 2004;27(10):589-94.

5. Yarrow JF, White LJ, McCoy SC, Borst SE. Training augments resistance exercise induced elevation of circulating brain derived neurotrophic factor (BDNF). Neurosci Lett. 2010;479(2):161-5.

6. Marston KJ, Newton MJ, Brown BM, Rainey-Smith SR, Bird S, Martins RN, et al. Intense resistance exercise increases peripheral brain-derived neurotrophic factor. J Sci Med Sport. 2017;20(10):899-903.

7. Castaneda C, Layne JE, Munoz-Orians L, Gordon PL, Walsmith J, Foldvari M, et al. A randomized controlled trial of resistance exercise training to improve glycemic control in older adults with type 2 diabetes. Diabetes Care. 2002;25(12):2335-41.

8. Colberg SR, Sigal RJ, Yardley JE, Riddell MC, Dunstan DW, Dempsey PC, et al. Physical activity/exercise and diabetes: a position statement of the American Diabetes Association. Diabetes Care. 2016:39(11):2065-79.

9. Billinger SA, Arena R, Bernhardt J, Eng JJ, Franklin BA, Johnson CM, et al. Physical activity and exercise recommendations for stroke survivors: a statement for healthcare professionals from the American Heart Association/American Stroke Association. Stroke. 2014:45(8):2532-53.

10. Williams MA, Haskell WL, Ades PA, Amsterdam EA, Bittner V, Franklin BA, et al. Resistance exercise in individuals with and without cardiovascular disease: 2007 update. Circulation. 2007;116(5):572-84.
11. Price KJ, Gordon BA, Bird SR, Benson AC. A review of guidelines for cardiac rehabilitation exercise programmes: is there an international consensus? Eur J Prev Cardiol. 2016;23(16):1715-33.

12. Edwards MR, Martin DH, Hughson RL. Cerebral hemodynamics and resistance exercise. Med Sci Sports Exerc. 2002;34(7):1207-11.

13. Haykowsky M, Findlay J, Ignaszewski A. Aneurysmal subarachnoid hemorrhage associated with weight training: three case reports. LWW; 1996.

14. Vlak MH, Rinkel GJ, Greebe P, van der Bom JG, Algra A. Trigger factors and their attributable risk for rupture of intracranial aneurysms: a case-crossover study. Stroke. 2011;42(7):1878-82

15. Compton D, Hill P, Sinclair J. Weight-lifters' blackout. Lancet. 1973;302(7840):1234-7.

16. Ainslie PN, Ashmead JC, Ide K, Morgan BJ, Poulin MJ. Differential responses to $\mathrm{CO}_{2}$ and sympathetic stimulation in the cerebral and femoral circulations in humans. J Physiol. 2005;566(2):613-24.

17. Willie CK, Tzeng YC, Fisher JA, Ainslie PN. Integrative regulation of human brain blood flow. J Physiol. 2014;592(5):841-59.

18. Filosa JA, Iddings JA. Astrocyte regulation of cerebral vascular tone. Am J Physiol Heart Circ Physiol. 2013;305:H609-H19.

19. Aaslid R, Lindegaard KF, Sorteberg W, Nornes H. Cerebral autoregulation dynamics in humans. Stroke. 1989;20(1):45-52.

20. Ogoh S, Sato K, Nakahara H, Okazaki K, Subudhi AW, Miyamoto T. Effect of acute hypoxia on blood flow in vertebral and internal carotid arteries. Exp Physiol. 2013;98(3):692-8.

21. Willie CK, Macleod DB, Shaw AD, Smith KJ, Tzeng YC, Eves ND, et al. Regional brain blood flow in man during acute changes in arterial blood gases. J Physiol. 2012;590(14):3261-75.

22. Ogoh S, Brothers RM, Barnes Q, Eubank WL, Hawkins MN, Purkayastha S. The effect of changes in cardiac output on middle cerebral artery mean blood velocity at rest and during exercise. J Physiol. 2005;569(2):697-704.

23. Hamner J, Tan CO, Lee K, Cohen MA, Taylor JA. Sympathetic control of the cerebral vasculature in humans. Stroke. 2010;41(1):102-9.

24. Ogoh S, Sørensen H, Hirasawa A, Sasaki H, Washio T, Hashimoto T, et al. Dynamic cerebral autoregulation is unrelated to decrease in external carotid artery blood flow during acute hypotension in healthy young men. Exp Physiol. 2016;101(8):1040-9.

25. Saleem S, Teal PD, Kleijn WB, Ainslie PN, Tzeng Y-C. Identification of human sympathetic neurovascular control using multivariate wavelet decomposition analysis. Am J Physiol Heart Circ Physiol. 2016:311(3):H837-H48.

26. Ainslie PN, Duffin J. Integration of cerebrovascular $\mathrm{CO} 2$ reactivity and chemoreflex control of breathing: mechanisms of regulation, measurement, and interpretation. Am J Phys Regul Integr Comp Phys. 2009;296(5):R1473-R95.

27. Kety SS, Schmidt CF. The effects of active and passive hyperventilation on cerebral blood flow, cerebral oxygen consumption, cardiac output, and blood pressure of normal young men. J Clin Investig. 1946;25(1):107-19.

28. Battisti-Charbonney A, Fisher J, Duffin J. The cerebrovascular response to carbon dioxide in humans. J Physiol. 2011;589(12):3039-48.

29. Kety SS, Schmidt CF. The effects of altered arterial tensions of carbon dioxide and oxygen on cerebral blood flow and cerebral oxygen consumption of normal young men. J Clin Investig. 1948:27(4):484-92.

30. Smith KJ. Ainslie PN. Exp Physiol: Regulation of cerebral blood flow and metabolism during exercise; 2017.

31. Lassen NA. Cerebral blood flow and oxygen consumption in man. Physiol Rev. 1959:39(2):183-238.

32. Tzeng Y-C, Ainslie PN. Blood pressure regulation IX: cerebral autoregulation under blood pressure challenges. Eur J Appl Physiol. 2013:1-15.

33. Lucas SJE, Tzeng YC, Galvin SD, Thomas KN, Ogoh S, Ainslie PN. Influence of changes in blood pressure on cerebral perfusion and oxygenation. Hypertension. 2010;55(3):698-705.

34. Zhang R, Behbehani $K$, Levine BD. Dynamic pressure-flow relationship of the cerebral circulation during acute increase in arterial pressure. J Physiol. 2009:587(11):2567-77.

35. Tan CO. Defining the characteristic relationship between arterial pressure and cerebral flow. J Appl Physiol. 2012;113:1194-200.

36. Numan T, Bain AR, Hoiland RL, Smirl JD, Lewis NC, Ainslie PN. Static autoregulation in humans: a review and reanalysis. Med Eng Phys. 2014;36(11):1487-95.

37. Ozturk ED, Tan CO. Human cerebrovascular function in health and disease: insights from integrative approaches. J Physiol Anthropol. 2018;37(1):4

38. Donnelly J, Budohoski KP, Smielewski P, Czosnyka M. Regulation of the cerebral circulation: bedside assessment and clinical implications. Crit Care. 2016:20(1):129.

39. MacDougall J, McKelvie R, Moroz D, Sale D, McCartney N, Buick F. Factors affecting blood pressure during heavy weight lifting and static contractions. J Appl Physiol. 1992;73(4):1590-7. 
40. Hamilton W, Woodbury R, Harper H. Arterial, cerebrospinal and venous pressures in man during cough and strain. Am J Physiol. 1944;141(1):42-50.

41. Pstras L, Thomaseth K, Waniewski J, Balzani I, Bellavere F. The Valsalva manoeuvre: physiology and clinical examples. Acta Physiol. 2016;217(2):103-19.

42. Pott F, van Lieshout JJ, Ide K, Madsen P, Secher NH. Middle cerebral artery blood velocity during a Valsalva maneuver in the standing position. J Appl Physiol. 2000;88(5):1545-50

43. Tiecks FP, Lam AM, Matta BF, Strebel S, Douville C, Newell DW. Effects of the Valsalva maneuver on cerebral circulation in healthy adults: a transcranial Doppler study. Stroke. 1995;26(8):1386-92.

44. Low PA, Tomalia VA, Park K-J. Autonomic function tests: some clinical applications. J Clin Neurol. 2013;9(1):1-8.

45. Perry BG, De Hamel T, Thomas KN, Wilson LC, Gibbons TD, Cotter JD. Cerebrovascular haemodynamics during isometric resistance exercise with and without the Valsalva manoeuvre. Eur J Appl Physiol. 2020:1-13.

46. Korner $P$, Tonkin A, Uther J. Reflex and mechanical circulatory effects of graded Valsalva maneuvers in normal man. J Appl Physiol. 1976:40(3):434-40.

47. Perry BG, Mündel T, Cochrane DJ, Cotter JD, Lucas SJ. The cerebrovascular response to graded Valsalva maneuvers while standing. Phys Rep. 2014;2(2): e00233

48. Goldberg $H$, Elisberg $E$, Katz L. The effects of the Valsalva-like maneuver upon the circulation in normal individuals and patients with mitral stenosis. Circulation. 1952:5(1):38-47.

49. Greenfield JC Jr, Rembert JC, Tindall GT. Transient changes in cerebral vascular resistance during the Valsalva maneuver in man. Stroke. 1984;15(1): 76-9.

50. Haykowsky MJ, Eves ND, Warburton DE, Findlay MJ. Resistance exercise, the Valsalva maneuver, and cerebrovascular transmural pressure. Med Sci Sports Exerc. 2003;35(1):65-8

51. Wilson MH. Monro-Kellie 2.0: The dynamic vascular and venous pathophysiological components of intracranial pressure. J Cereb Blood Flow Metab. 2016:36(8):1338-50.

52. Greenfield JC Jr, Tindall GT. Effect of acute increase in intracranial pressure on blood flow in the internal carotid artery of man. J Clin Investig. 1965; 44(8):1343

53. Kety SS, Shenkin HA, Schmidt CF. The effects of increased intracranial pressure on cerebral circulatory functions in man. J Clin Investig. 1948;27(4): 493.

54. Bloomfield GL, Ridings PC, Blocher CR, Marmarou A, Sugerman HJ. A proposed relationship between increased intra-abdominal, intrathoracic and intracranial pressure. Crit Care Med. 1997;25(3):496-503.

55. Perry BG, Schlader ZJ, Barnes MJ, Cochrane DJ, Lucas SJ, Mündel T. Hemodynamic response to upright resistance exercise: effect of load and repetition. Med Sci Sports Exerc. 2014:46:479-87.

56. Zhang R, Zuckerman JH, Iwasaki K, Wilson TE, Crandall CG, Levine BD. Autonomic neural control of dynamic cerebral autoregulation in humans. Circulation. 2002;106(14):1814-20.

57. Perry BG, Cotter JD, Mejuto G, Mündel T, Lucas SJ. Cerebral hemodynamics during graded Valsalva maneuvers. Front Physiol. 2014;5:1-7.

58. Brassard P, Tymko MM, Ainslie PN. Sympathetic control of the brain circulation: appreciating the complexities to better understand the controversy. Auton Neurosci. 2017;207:37-47.

59. Verbree J, Bronzwaer A, van Buchem MA, Daemen MJ, van Lieshout JJ, van Osch MJ. Middle cerebral artery diameter changes during rhythmic handgrip exercise in humans. J Cereb Blood Flow Metab. 2017;37(8):2921-7.

60. Cassaglia PA, Griffiths RI, Walker AM. Sympathetic nerve activity in the superior cervical ganglia increases in response to imposed increases in arterial pressure. Am J Phys Regul Integr Comp Phys. 2008;294(4):1255-61.

61. Zhang R, Crandall CG, Levine BD. Cerebral hemodynamics during the valsalva maneuver insights from ganglionic blockade. Stroke. 2004;35(4): 843-7.

62. Dickerman R, McConathy W, Smith G, East J, Rudder L. Middle cerebra artery blood flow velocity in elite power athletes during maximal weightlifting. Neurol Res. 2000;22(4):337-40.

63. Koch FDA, Ivers M, Gehrt A, Schnoor P, Rump A, Rieckert H. Cerebral autoregulation is temporarily disturbed in the early recovery phase after dynamic resistance exercise. Clin Auton Res. 2005;15(2):83-91.

64. Moralez G, Romero SA, Rickards CA, Ryan KL, Convertino VA, Cooke WH. Effects of dehydration on cerebrovascular control during standing after heavy resistance exercise. J Appl Physiol. 2012;112(11): 1875-83.
65. Romero SA, Cooke WH. Hyperventilation before resistance exercise: cerebral hemodynamics and orthostasis. Med Sci Sports Exerc. 2007;39(8):1302-7.

66. Braz ID, Scott C, Simpson LL, Springham EL, Tan BW, Balanos GM, et al. Influence of muscle metaboreceptor stimulation on middle cerebral artery blood velocity in humans. Exp Physiol. 2014;99(11):1478-87.

67. Fernandes IA, Mattos JD, Campos MO, Machado AC, Rocha MP, Rocha NG, et al. Selective a 1-adrenergic blockade disturbs the regional distribution of cerebral blood flow during static handgrip exercise. Am J Physiol Heart Circ Physiol. 2016;310(11):H1541-H8.

68. Friedman D, Friberg $L$, Mitchell J, Secher N. Effect of axillary blockade on regional cerebral blood flow during static handgrip. J Appl Physiol. 1991; 71(2):651-6.

69. Giller CA, Giller AM, Cooper CR, Hatab MR. Evaluation of the cerebral hemodynamic response to rhythmic handgrip. J Appl Physiol. 2000;88(6): 2205-13.

70. Hartwich D, Fowler KL, Wynn LJ, Fisher JP. Differential responses to sympathetic stimulation in the cerebral and brachial circulations during rhythmic handgrip exercise in humans. Exp Physiol. 2010;95(11):1089-97.

71. Hirasawa A, Sato K, Yoneya M, Sadamoto T, Bailey DM, Ogoh S. Heterogeneous regulation of brain blood flow during low-intensity resistance exercise. Med Sci Sports Exerc. 2016:48(9):1829-34.

72. Imms F, Russo F, lyawe V, Segal M. Cerebral blood flow velocity during and after sustained isometric skeletal muscle contractions in man. Clin Sci. 1998; 94(4):353-8

73. Ide K, Pott F, Van Lieshout J, Secher N. Middle cerebral artery blood velocity depends on cardiac output during exercise with a large muscle mass. Acta Physiol Scand. 1998;162(1):13-20.

74. Jorgensen LG, Perko G, Payne G, Secher NH. Effect of limb anesthesia on middle cerebral response to handgrip. Am J Physiol Heart Circ Physiol. 1993; 264(2):H553-H9.

75. Jorgensen L, Perko M, Hanel B, Schroeder T, Secher N. Middle cerebral artery flow velocity and blood flow during exercise and muscle ischemia in humans. J Appl Physiol. 1992;72(3):1123-32.

76. Kim Y-S, Krogh-Madsen R, Rasmussen P, Plomgaard P, Ogoh S, Secher NH, et al. Effects of hyperglycemia on the cerebrovascular response to rhythmic handgrip exercise. Am J Physiol Heart Circ Physiol. 2007;293(1):H467-H73.

77. Linkis P, Jorgensen LG, Olesen H, Madsen P, Lassen N, Secher N. Dynamic exercise enhances regional cerebral artery mean flow velocity. J Appl Physiol. 1995;78(1):12-6.

78. Ogoh S, Sato K, Akimoto T, Oue A, Hirasawa A, Sadamoto T. Dynamic cerebral autoregulation during and after handgrip exercise in humans. $J$ Appl Physiol. 2010;108(6):1701-5

79. Pott F, Van Lieshout JJ, Ide K, Madsen P, Secher NH. Middle cerebral artery blood velocity during intense static exercise is dominated by a Valsalva maneuver. J Appl Physiol. 2003:94(4):1335-44.

80. Vianna LC, Araújo CGS, Fisher JP. Influence of central command and muscle afferent activation on anterior cerebral artery blood velocity responses to calf exercise in humans. J Appl Physiol. 2009;107(4):1113-20.

81. Washio T, Sasaki H, Ogoh S. Transcranial Doppler-determined change in posterior cerebral artery blood flow velocity does not reflect vertebral artery blood flow during exercise. Am J Physiol Heart Circ Physiol. 2017;312(4): H827-H31.

82. Washio T, Vranish JR, Kaur J, Young BE, Katayama K, Fadel PJ, et al. Acute reduction in posterior cerebral blood flow following isometric handgrip exercise is augmented by lower body negative pressure. Phys Rep. 2018;6(20):e13886.

83. Ogoh S, Washio T, Paton JF, Fisher JP, Petersen LG. Gravitational effects on intracranial pressures and blood flow regulation in young men: a potential shunting role for the external carotid artery. J Appl Physiol. 2020.

84. Abidi S, Nili M, Serna S, Kim S, Hazlett C, Edgell H. Influence of sex, menstrual cycle, and oral contraceptives on cerebrovascular resistance and cardiorespiratory function during Valsalva or standing. J Appl Physiol. 2017; 123(2):375-86

85. Deegan BM, Devine ER, Geraghty MC, Jones E, ÓLaighin G, Serrador JM. The relationship between cardiac output and dynamic cerebral autoregulation in humans. J Appl Physiol. 2010;109(5):1424-31.

86. Favre ME, Lim V, Falvo MJ, Serrador JM. Cerebrovascular reactivity and cerebral autoregulation are improved in the supine posture compared to upright in healthy men and women. PLoS One. 2020;15(3):e0229049.

87. Minhas J, Panerai R, Robinson T. Sex differences in cerebral haemodynamics across the physiological range of $\mathrm{PaCO}$. Physiol Meas. 2018;39(10):105009. 
88. Miller KB, Howery AJ, Rivera-Rivera LA, Johnson SC, Rowley HA, Wieben O, et al. Age-related reductions in cerebrovascular reactivity using 4D flow MR Front Aging Neurosci. 2019;11:281.

89. Labrecque L, Rahimaly K, Imhoff S, Paquette M, Le Blanc O, Malenfant S, et al. Dynamic cerebral autoregulation is attenuated in young fit women. Phys Rep. 2019;7(2):e13984.

90. Favre ME, Serrador JM. Sex differences in cerebral autoregulation is unaffected by menstrual cycle phase in young, healthy women. Am J Physiol Heart Circ Physiol. 2019;316:H920-H33. https://doi.org/10.1152/a jpheart.00474.2018.

91. Hackett DA, Chow C-M. The Valsalva maneuver: its effect on intraabdominal pressure and safety issues during resistance exercise. J Strength Cond Res. 2013;27(8):2338-45.

92. Garber CE, Blissmer B, Deschenes MR, Franklin BA, Lamonte MJ, Lee I-M, et al. American College of Sports Medicine position stand. Quantity and quality of exercise for developing and maintaining cardiorespiratory, musculoskeletal, and neuromotor fitness in apparently healthy adults: guidance for prescribing exercise. Med Sci Sports Exerc. 2011;43(7):1334-59.

93. Harman EA, Frykman PN, Clagett ER, Kraemer WJ. Intra-abdominal and intrathoracic pressures during lifting and jumping. Med Sci Sports Exerc. 1988; 20(2):195-201.

94. Kraemer WJ, Ratamess NA. Fundamentals of resistance training: progression and exercise prescription. Med Sci Sports Exerc. 2004;36(4):674-88.

95. Dawson SL, Panerai RB, Potter JF. Critical closing pressure explains cerebral hemodynamics during the Valsalva maneuver. J Appl Physiol. 1999;86(2): 675-80.

96. Sale D, Moroz D, McKelvie R, MacDougall J, McCartney N. Comparison of blood pressure response to isokinetic and weight-lifting exercise. Eur J Appl Physiol Occup Physiol. 1993;67(2):115-20.

97. Kagaya A, Homma S. Brachial arterial blood flow during static handgrip exercise of short duration at varying intensities studied by a Doppler ultrasound method. Acta Physiol Scand. 1997;160(3):257-65.

98. Ng A, Agre J, Hanson P, Harrington M, Nagle F. Influence of muscle length and force on endurance and pressor responses to isometric exercise. J Appl Physiol. 1994;76(6):2561-9.

99. Stewart JM, Montgomery LD, Glover JL, Medow MS. Changes in regional blood volume and blood flow during static handgrip. Am J Physiol Heart Circ Physiol. 2007;292(1):H215-H23.

100. MCNeil CJ, Allen MD, Olympico E, Shoemaker JK, Rice CL. Blood flow and muscle oxygenation during low, moderate, and maximal sustained isometric contractions. Am J Phys Regul Integr Comp Phys. 2015;309(5):R475-R81.

101. MacDougall J, Tuxen D, Sale D, Moroz J, Sutton J. Arterial blood pressure response to heavy resistance exercise. J Appl Physiol. 1985;58(3):785-90.

102. Lewis SF, Snell PG, Taylor WF, Hamra M, Graham RM, Pettinger WA, et al. Role of muscle mass and mode of contraction in circulatory responses to exercise. J Appl Physiol. 1985;58(1):146-51.

103. Mitchell J, Payne F, Saltin B, Schibye B. The role of muscle mass in the cardiovascular response to static contractions. J Physiol. 1980;309(1):45-54.

104. Palatini P, Mos L, Munari L, Valle F, Del Torre M, Rossi A, et al. Blood pressure changes during heavy-resistance exercise. J Hypertens Suppl. 1989; 7(6):S72-3.

105. McCartney N, McKelvie R, Martin J, Sale D, MacDougall J. Weight-traininginduced attenuation of the circulatory response of older males to weight lifting. J Appl Physiol. 1993;74(3):1056-60.

106. Poton R, Polito MD. Hemodynamic response to resistance exercise with and without blood flow restriction in healthy subjects. Clin Physiol Funct Imaging. 2016;36(3):231-6.

107. Libardi CA, Catai AM, Miquelini M, Borghi-Silva A, Minatel V, Alvarez IF, et al. Hemodynamic responses to blood flow restriction and resistance exercise to muscular failure. Int J Sports Med. 2017:38(02):134-40.

108. Niewiadomski W, Pilis W, Laskowska D, Gasiorowska A, Cybulski G, Strasz A. Effects of a brief Valsalva manoeuvre on hemodynamic response to strength exercises. Clin Physiol Funct Imaging. 2012;32(2):145-57.

109. Lentini AC, McKelvie RS, McCartney N, Tomlinson CW, MacDougall JD. Left ventricular response in healthy young men during heavy-intensity weightlifting exercise. J Appl Physiol. 1993;75(6):2703-10.

110. Paulo AC. Tricoli V. Queiroz AC: Laurentino G, Forjaz CL. Blood pressure response during resistance training of different work to rest ratio. J Strength Cond Res; 2017.

111. Balmain B, Stewart G, Yamada A, Chan J, Haseler L, Sabapathy S. The impact of an experimentally induced increase in arterial blood pressure on left ventricular twist mechanics. Exp Physiol. 2016;101(1):124-34.
112. Lalande S, Sawicki CP, Baker JR, Shoemaker JK. Effect of age on the hemodynamic and sympathetic responses at the onset of isometric handgrip exercise. J Appl Physiol. 2013;116(2):222-7.

113. Stöhr EJ, Stembridge M, Shave R, Samuel TJ, Stone K, Esformes Jl. Systolic and diastolic left ventricular mechanics during and after resistance exercise. Med Sci Sports Exerc. 2017:49(10):2025-31.

114. O'Donnell TV, Mcllroy MB. The circulatory effects of squatting. Am Heart J. 1962;64(3):347-56.

115. Krediet CP, de Bruin IG, Ganzeboom KS, Linzer M, van Lieshout JJ, Wieling W. Leg crossing, muscle tensing, squatting, and the crash position are effective against vasovagal reactions solely through increases in cardiac output. J Appl Physiol. 2005;99(5):1697-703.

116. Ainslie PN, Ogoh S. Regulation of cerebral blood flow in mammals during chronic hypoxia: a matter of balance. Exp Physiol. 2010;95(2):251-62.

117. Ogoh S, Dalsgaard M, Secher N, Raven P. Dynamic blood pressure control and middle cerebral artery mean blood velocity variability at rest and during exercise in humans. Acta Physiol. 2007;191(1):3-14.

118. Ogoh S, Hayashi N, Inagaki M, Ainslie PN, Miyamoto T. Interaction between the ventilatory and cerebrovascular responses to hypo-and hypercapnia at rest and during exercise. J Physiol. 2008;586(17):4327-38.

119. Ainslie PN, Barach A, Murrell C, Hamlin M, Hellemans J, Ogoh S. Alterations in cerebral autoregulation and cerebral blood flow velocity during acute hypoxia: rest and exercise. Am J Physiol Heart Circ Physiol. 2007;292(2): H976-H83.

120. Miyazawa T, Horiuchi M, Ichikawa D, Subudhi AW, Sugawara J, Ogoh S. Face cooling with mist water increases cerebral blood flow during exercise: effect of changes in facial skin blood flow. Front Physiol. 2012;3.

121. Ide K, Boushel R, Sørensen $H$, Fernandes A, Cai Y, Pott F, et al. Middle cerebral artery blood velocity during exercise with beta-1 adrenergic and unilateral stellate ganglion blockade in humans. Acta Physiol Scand. 2000; 170(1):33-8

122. Jorgensen $L G$, Perko $G$, Secher $N H$. Regional cerebral artery mean flow velocity and blood flow during dynamic exercise in humans. J Appl Physiol. 1992;73(5):1825-30.

123. Sato K, Ogoh S, Hirasawa A, Oue A, Sadamoto T. The distribution of blood flow in the carotid and vertebral arteries during dynamic exercise in humans. J Physiol. 2011;589(11):2847-56.

124. Madsen PL, Sperling BRK, Warming T, Schmidt J, Secher N, Wildschiodtz G, et al. Middle cerebral artery blood velocity and cerebral blood flow and $\mathrm{O}_{2}$ uptake during dynamic exercise. J Appl Physiol. 1993;74(1):245-50.

125. Herholz K, Buskies W, Rist M, Pawlik G, Hollmann W, Heiss W. Regional cerebral blood flow in man at rest and during exercise. J Neurol. 1987; 234(1):9-13.

126. Ogoh S, Fadel PJ, Zhang R, Selmer C, Jans $\varnothing$, Secher NH, et al. Middle cerebral artery flow velocity and pulse pressure during dynamic exercise in humans. Am J Physiol Heart Circ Physiol. 2005;288(4):H1526-H31.

127. Faull O, Cotter J, Lucas S. Cerebrovascular responses during rowing: do circadian rhythms explain morning and afternoon performance differences? Scand J Med Sci Sports. 2015;25(4):467-75.

128. Pott F, Knudsen L, Nowak M, Nielsen H, Hanel B, Secher N. Middle cerebral artery blood velocity during rowing. Acta Physiol Scand. 1997;160(3):251-5.

129. Furlong RJ, Weaver SR, Sutherland R, Burley CV, Imi GM, Lucas RA, et al. Exercise-induced elevations in cerebral blood velocity are greater in running compared to cycling at higher intensities. Phys Rep. 2020;8(15):e14539.

130. Lyngeraa T, Pedersen LM, Mantoni T, Belhage B, Rasmussen L, van Lieshout J, et al. Middle cerebral artery blood velocity during running. Scand J Med Sci Sports. 2013;23(1):e32-e7.

131. Green DJ, Hopman MT, Padilla J, Laughlin MH, Thijssen DH. Vascular adaptation to exercise in humans: role of hemodynamic stimuli. Physiol Rev. 2017;97(2):495-528.

132. Brys M, Brown CM, Marthol H, Franta R, Hilz MJ. Dynamic cerebral autoregulation remains stable during physical challenge in healthy persons. Am J Physiol Heart Circ Physiol. 2003;285(3):H1048-H54.

133. Tsukamoto $H$, Hashimoto $T$, Olesen ND, Petersen LG, Sørensen H, Nielsen $H B$, et al. Dynamic cerebral autoregulation is maintained during highintensity interval exercise. Med Sci Sports Exerc. 2019;51(2):372-8.

134. Hamner J, Ishibashi K, Tan CO. Revisiting human cerebral blood flow responses to augmented blood pressure oscillations. J Physiol. 2019:597(6):1553-64.

135. Zhang R, Zuckerman JH, Giller CA, Levine BD. Transfer function analysis of dynamic cerebral autoregulation in humans. Am J Physiol Heart Circ Physiol. 1998;274(1):233-41. 
136. Brassard P, Ferland-Dutil H, Smirl JD, Paquette M, Le Blanc O, Malenfant S, et al. Evidence for hysteresis in the cerebral pressure-flow relationship in healthy men. Am J Physiol Heart Circ Physiol. 2017;312(4):H701-H4.

137. Tzeng YC, Willie CK, Atkinson G, Lucas SJE, Wong A, Ainslie PN. Cerebrovascular regulation during transient hypotension and hypertension in humans. Hypertension. 2010;56(2):268-73.

138. Panerai RB, Barnes SC, Nath M, Ball N, Robinson TG, Haunton VJ. Directional sensitivity of dynamic cerebral autoregulation in squat-stand maneuvers. Integrative and Comparative Physiology: American Journal of PhysiologyRegulatory; 2018.

139. Claassen JA, Levine BD, Zhang R. Dynamic cerebral autoregulation during repeated squat-stand maneuvers. J Appl Physiol (1985). 2009;106(1):153-60. https://doi.org/10.1152/japplphysiol.90822.2008.

140. Miyachi M, Kawano H, Sugawara J, Takahashi K, Hayashi K, Yamazaki K, et al. Unfavorable effects of resistance training on central arterial compliance a randomized intervention study. Circulation. 2004;110(18):2858-63.

141. Tzeng YC, Chan GSH, Willie CK, Ainslie PN. Determinants of human cerebral pressure-flow velocity relationships: new insights from vascular modelling and Ca2+ channel blockade. J Physiol. 2011;589(13):3263-74.

142. Perry BG, Cotter JD, Korad S, Lark S, Labrecque L, Brassard $P$, et al. Implications of habitual endurance and resistance exercise for dynamic cerebral autoregulation. Exp Physiol. 2019. https://doi.org/10.1113/EP087675.

143. Nakamura N, Muraoka I. Resistance training augments cerebral blood flow pulsatility: cross-sectional study. Am J Hypertens. 2018;31(7):811-7.

144. Zhang R, Witkowski S, Fu Q, Claassen JAHR, Levine BD. Cerebral hemodynamics after short-and long-term reduction in blood pressure in mild and moderate hypertension. Hypertension. 2007;49(5):1149-55.

145. Sato K, Hirasawa A, Tsunoda N, Taniguchi Y, Sadamoto T. Cerebrovascular response during heavy upper body exercise: effect of mode of ventilation on blood flow velocity in the middle cerebral artery. Oxygen Transport to Tissue XXXI: Springer; 2010. p. 347-52.

146. Yamaguchi Y, Kashima H, Fukuba Y, Hayashi N. Cerebral blood flow and neurovascular coupling during static exercise. J Physiol Sci. 2014;64(3):195201.

147. Sato K, Fisher JP, Seifert T, Overgaard M, Secher NH, Ogoh S. Blood flow in internal carotid and vertebral arteries during orthostatic stress. Exp Physiol. 2012;97(12):1272-80.

148. Ogoh S, Sato K, Okazaki K, Miyamoto T, Hirasawa A, Sadamoto T, et al. Blood flow in internal carotid and vertebral arteries during graded lower body negative pressure in humans. Exp Physiol. 2015:100(3):259-66.

149. Lewis NC, Smith KJ, Bain AR, Wildfong KW, Numan T, Ainslie PN. Impact of transient hypotension on regional cerebral blood flow in humans. Clin Sci. 2015;129(2):169-78.

150. Sato K, Sadamoto T, Hirasawa A, Oue A, Subudhi AW, Miyazawa T, et al. Differential blood flow responses to $\mathrm{CO}_{2}$ in human internal and external carotid and vertebral arteries. J Physiol. 2012;590(14):3277-90.

151. Skow RJ, MacKay CM, Tymko MM, Willie CK, Smith KJ, Ainslie PN, et al. Differential cerebrovascular $\mathrm{CO}_{2}$ reactivity in anterior and posterior cerebral circulations. Respir Physiol Neurobiol. 2013;189(1):76-86.

152. Rogers HB, Schroeder T, Secher NH, Mitchell JH. Cerebral blood flow during static exercise in humans. J Appl Physiol. 1990;68(6):2358-61.

153. Brown SP, Clemons JM, He Q, Liu S. Effects of resistance exercise and cycling on recovery blood pressure. J Sports Sci. 1994;12(5):463-8. https:// doi.org/10.1080/02640419408732196.

154. Fisher MM. The effect of resistance exercise on recovery blood pressure in normotensive and borderline hypertensive women. J Strength Cond Res. 2001;15(2):210-6.

155. de Vos NJ, Singh NA, Ross DA, Stavrinos TM, Orr R, Singh MAF. Continuous hemodynamic response to maximal dynamic strength testing in older adults. Arch Phys Med Rehabil. 2008;89(2):343-50.

156. Lefferts WK, Augustine JA, Heffernan KS. Effect of acute resistance exercise on carotid artery stiffness and cerebral blood flow pulsatility. Front Physiol. 2014:5:101.

157. Sejersted O, Hargens AR, Kardel KR, Blom P, Jensen O, Hermansen L. Intramuscular fluid pressure during isometric contraction of human skeletal muscle. J Appl Physiol. 1984;56(2):287-95.

158. Fahs CA, Heffernan KS, Fernhall B. Hemodynamic and vascular response to resistance exercise with L-arginine. Med Sci Sports Exerc. 2009;41(4):773-9.

159. Barcroft H, Millen J. The blood flow through muscle during sustained contraction. J Physiol. 1939;97(1):17-31.
160. Sjøgaard G, Savard G, Juel C. Muscle blood flow during isometric activity and its relation to muscle fatigue. Eur J Appl Physiol Occup Physiol. 1988; 57(3):327-35.

161. Rossberg F, Peňaz J. Initial cardiovascular response on change of posture from squatting to standing. Eur J Appl Physiol Occup Physiol. 1988;57(1):937.

162. Folkow B, Haglund $U$, Jodal M, Lundgren O. Blood flow in the calf muscle of man during heavy rhythmic exercise. Acta Physiol Scand. 1971;81(2):157-63.

163. Walløe $L$, Wesche J. Time course and magnitude of blood flow changes in the human quadriceps muscles during and following rhythmic exercise. J Physiol. 1988:405(1):257-73.

164. Corcondilas A, Koroxenidis GT, Shepherd JT. Effect of a brief contraction of forearm muscles on forearm blood flow. J Appl Physiol. 1964;19(1):142-6.

165. Sullivan J, Hanson P, Rahko PS, Folts JD. Continuous measurement of left ventricular performance during and after maximal isometric deadlift exercise. Circulation. 1992;85(4):1406-13.

166. Smit AAJ, Halliwill JR, Low PA, Wieling W. Pathophysiological basis of orthostatic hypotension in autonomic failure. J Physiol. 1999;519(1):1-10.

167. Harms M, Wesseling K, Pott F, Jenstrup M, Van Goudoever J, Secher N, et al. Continuous stroke volume monitoring by modelling flow from non-invasive measurement of arterial pressure in humans under orthostatic stress. Clin Sci. 1999:97(3):291-301.

168. Wieling W, Krediet C, van Dijk N, Linzer M, Tschakovsky M. Initial orthostatic hypotension: review of a forgotten condition. Clin Sci. 2007;112:157-65.

169. Thomas KN, Cotter JD, Galvin SD, Williams MJA, Willie CK, Ainslie PN. Initial orthostatic hypotension is unrelated to orthostatic tolerance in healthy young subjects. J Appl Physiol. 2009;107(2):506-17.

170. Schondorf R, Benoit J, Wein T. Cerebrovascular and cardiovascular measurements during neurally mediated syncope induced by head-up tilt. Stroke. 1997;28(8):1564-8.

171. Poulin MJ, Liang PJ, Robbins PA. Fast and slow components of cerebral blood flow response to step decreases in end-tidal in humans. J Appl Physiol. 1998:85(2):388-97.

172. Pollock ML, Franklin BA, Balady GJ, Chaitman BL, Fleg JL, Fletcher B, et al. Resistance exercise in individuals with and without cardiovascular disease: benefits, rationale, safety, and prescription an advisory from the committee on exercise, rehabilitation, and prevention, council on clinical cardiology, American Heart Association. Circulation. 2000;101(7):828-33.

173. Shaw BS, Shaw I, Brown GA. Resistance exercise is medicine: Strength training in health promotion and rehabilitation. Int J Ther Rehabil. 2015; 22(8):385-9.

174. Ainslie PN, Hoiland RL. Transcranial Doppler ultrasound: valid, invalid, or both?: Am Physiological Soc; 2014.

175. Coverdale NS, Gati JS, Opalevych O, Perrotta A, Shoemaker JK. Cerebral blood flow velocity underestimates cerebral blood flow during modest hypercapnia and hypocapnia. J Appl Physiol. 2014;117(10):1090-6.

176. Verbree J, Bronzwaer A-SG, Ghariq E, Versluis MJ, Daemen MJ, van Buchem MA, et al. Assessment of middle cerebral artery diameter during hypocapnia and hypercapnia in humans using ultra-high-field MRI. J Appl Physiol. 2014; 117(10):1084-9.

177. Thomas KN, Lewis NC, Hill BG, Ainslie PN. Technical recommendations for the use of carotid duplex ultrasound for the assessment of extracranial blood flow. Am J Phys Regul Integr Comp Phys. 2015;309(7):R707-R20.

178. Thomas KN, Gibbons TD, Necas M. Letter to the Editor: Imaging Transcranial Doppler Ultrasound: is it giving us an accurate picture of cerebral hemodynamics? Am J Phys Regul Integr Comp Phys. 2020;319(1):R79-80.

179. Tymko MM, Ainslie PN, Smith KJ. Evaluating the methods used for measuring cerebral blood flow at rest and during exercise in humans. Eur J Appl Physiol. 2018;118(8):1527-38.

\section{Publisher's Note}

Springer Nature remains neutral with regard to jurisdictional claims in published maps and institutional affiliations. 